\title{
A non-linear dynamical approach to belief revision in cognitive behavioral therapy
}

\section{David Kronemyer* and Alexander Bystritsky}

Anxiety and Related Disorders Program, David Geffen School of Medicine, Semel Institute for Neuroscience and Human Behavior, University of California, Los Angeles, CA, USA

\section{Edited by:}

Tobias A. Mattei, Ohio State

University, USA

\section{Reviewed by:}

Tobias A. Mattei, Ohio State

University, USA

Fatemeh Bakouie, Amirkabir

University of Technology, Iran

*Correspondence:

David Kronemyer, Anxiety and Related Disorders Program, David Geffen School of Medicine, Semel Institute for Neuroscience and Human Behavior, University of California, 300 UCLA Medical Plaza,

Room 2330, Los Angeles, CA

90095-6968, USA

e-mail:dkronemyer@

mednet.ucla.edu
Belief revision is the key change mechanism underlying the psychological intervention known as cognitive behavioral therapy (CBT). It both motivates and reinforces new behavior. In this review we analyze and apply a novel approach to this process based on AGM theory of belief revision, named after its proponents, Carlos Alchourrón, Peter Gärdenfors and David Makinson. AGM is a set-theoretical model. We reconceptualize it as describing a non-linear, dynamical system that occurs within a semantic space, which can be represented as a phase plane comprising all of the brain's attentional, cognitive, affective and physiological resources. Triggering events, such as anxiety-producing or depressing situations in the real world, or their imaginal equivalents, mobilize these assets so they converge on an equilibrium point. A preference function then evaluates and integrates evidentiary data associated with individual beliefs, selecting some of them and comprising them into a belief set, which is a metastable state. Belief sets evolve in time from one metastable state to another. In the phase space, this evolution creates a heteroclinic channel. AGM regulates this process and characterizes the outcome at each equilibrium point. Its objective is to define the necessary and sufficient conditions for belief revision by simultaneously minimizing the set of new beliefs that have to be adopted, and the set of old beliefs that have to be discarded or reformulated. Using AGM, belief revision can be modeled using three (and only three) fundamental syntactical operations performed on belief sets, which are expansion; revision; and contraction. Expansion is like adding a new belief without changing any old ones. Revision is like adding a new belief and changing old, inconsistent ones. Contraction is like changing an old belief without adding any new ones. We provide operationalized examples of this process in action.

Keywords: AGM theory, belief revision, cognitive behavioral therapy, cognitive restructuring, exposure/response prevention, non-linear dynamical psychiatry, systematic desensitization
Non-linear dynamical psychiatry recently has taken two different directions. The first is the granular description of neurological systems from a bottom-up, micro level, in order to characterize a cognitive phenotype such as emotion or attention (illustrative is Rabinovich et al., 2010a). The second is the functional description of psychopathology and corollary intervention strategies from a top-down, macro level, in order to characterize the course and progression of psychiatric disorders (illustrative is Bystritsky et al., 2012). Drawing on both, in this review we set forth a theory of belief revision for the intervention strategy known as cognitive behavioral therapy (CBT). CBT postulates that psychiatric disorders such as anxiety and depression are not caused by acts, transactions, events or circumstances in the real world, or by one's imaginal reconstruction of them. Rather, they result from one's attitude, orientation or outlook toward them. Persons who are anxious or depressed hold dysfunctional beliefs about themselves, others, their environment and the future. Dysfunctional beliefs are caused by an invalidating environment, deficient informationgathering practices and breakdowns in one's belief formation system (Warman et al., 2007). They often are accompanied by dysregulated emotions (Linehan, 1993). As a result, persons holding them engage in problematic or undesired behavior that is personally distressful or socially maladaptive, for example, anger, impulsivity, self-harm, self-isolation or substance abuse ("target behavior").

Belief revision is the primary therapeutic technology underlying CBT. As we will explain, it comes in two types. The first, called "cognitive restructuring," reformulates old beliefs and changes them into new ones. As a result, one is able to reregulate one's emotions and modify or abandon target behavior. The second results from behavioral change through a process called "systematic desensitization" or "exposure/response prevention." It extinguishes old, conditioned target behavior and introduces new more flexible, adaptive behavior. This in turn reformulates or discards old beliefs and reregulates emotions, reinforcing the newlylearned behavior. In both cases, the new behavior then stabilizes, consolidates and strengthens the new beliefs. Both are forms of belief revision: the former, more cognitively-based than behavioral; and the latter, more behaviorally-based than cognitive. Belief revision also reduces the intensity of interoceptive alarms activated by the sympathetic nervous system when stressed, such as those characteristic of panic (Khalsa et al., 2009; Domschke et al., 2010). CBT widely is regarded as the paradigm of an empirically-supported therapy (EST) (Butler et al., 2006), which 
should make it particularly amenable to a cognitive science-based approach.

Our central premise is that belief revision in CBT is an integral component of a non-linear dynamical process of psychological change as conceptualized, for example, by Bystritsky et al. (2013). Anxiety and mood disorders have three essential components, which are alarms, beliefs and coping strategies (A-B-C). Alarms can be evaluated using conventional metrics such as their frequency, intensity, duration and onset. Coping strategies-a form of behavior-can be evaluated by whether they are distressful, maladaptive, or effective in down-regulating the incidence of target behavior and the intensity of correlative alarms. Beliefs are more difficult to integrate into a theory of non-linear dynamical systems. They have several unique characteristics as cognitive phenotypes, which prevent them from fitting well into the canonical model. One might not even notice one has beliefs to begin with, unless and until they are activated by environmental triggers, interoceptive sensations or undesired behavioral consequences.

Alternatively, we propose and demonstrate a set-theoretical, semantically-based approach to belief revision known as AGM theory, and show how it is the most plausible candidate to perform belief revision within a non-linear, dynamical framework. AGM is an acronym of the last names of its inventors, Alchourrón et al. (1985). It sets forth the requirements for non-delusional belief change in light of new evidence, and that one's resulting updated knowledge base must meet, in order to remain intuitively appealing (Carnota and Rodríguez, 2011, p. 2). As we discuss at $\$ 3, A G M$ operationalizes the cognitive component of CBT. Its objective is to define the necessary and sufficient conditions for belief revision by simultaneously minimizing the set of new beliefs that have to be adopted, and the set of old beliefs that have to be discarded or reformulated. Using AGM, belief revision can be modeled using three (and only three) fundamental syntactical operations performed on belief sets, which are expansion; revision; and contraction. Expansion is like adding a new belief without changing any old ones. Revision is like adding a new belief and changing old, inconsistent ones. Contraction is like changing an old belief without adding any new ones.

\section{SOME RELEVANT CONSIDERATIONS ABOUT BELIEF}

The nature of belief and what it is to believe in something (a doxastic state) both long have been central pre-occupations of psychology and epistemology (Schwitzgebel, 2010). It is beyond the scope of this review to discuss exhaustively the voluminous literature on belief, which has accumulated relentlessly since antiquity. We will, however, briefly develop several characteristics of belief pertinent to its integration into a theory of non-linear dynamical systems, which any theory of belief revision must take into account ${ }^{1}$.

\footnotetext{
${ }^{1}$ Some of the other issues affecting beliefs that are beyond the scope of this review include (for starters): the subjective, phenomenological experience of belief; taxonomies of different types of beliefs; the relationship between beliefs and emotions; the role of memory; subjective probability theory; Bayesian epistemology; Dempster-Shafer theory; theories of reasoning; and rationality. In addition we do not here address objections such as logical omniscience, monotonicity and whether language (and beliefs) can be analyzed using a logical structure, to begin with.
}

A consensus definition is that beliefs are "states of mind that have the property of being about things-things in the world, as well as abstract things, events in the past and things only imagined" (Churchland and Churchland, 2013, p. 1). Russell (1921/2005) and colleagues famously developed a theory of propositions and propositional attitudes. What beliefs are about is their substantive propositional content, i.e., (that " $x$ "). Belief is an attitude, orientation or outlook toward that propositional content, i.e., BEL(“ $x$ "). The set of all of one's beliefs at time $t_{1}$ is one's knowledge base $k_{1}$. Beliefs are different than simple reference to people, places or things; informal or colloquial uses (Grice, 1975); as well as other modes of discourse such as performatives (Austin, $1962)^{2}$. While all of its individual elements are controversial in various respects, for our purposes, Figure 1 depicts the standard model of belief, with components including perceptual, cognitive, emotional, linguistic and behavioral processing.

\section{BELIEFS ARE BASED ON EVIDENCE}

Evidence is a set of epistemological claims adduced to support a belief set. Relevant evidence enables one to devise and then test various hypotheses the belief set generates (Glymour, 1975; Hartmann and Sprenger, 2010). One is justified in believing that " $x$ " to the extent one has good evidence for " $x$ " (Feldman and Conee, 1985; Joyce, 2011). In the case of psychiatric disorders such as anxiety or depression, evidentiary data are things one might cite or rely on to support a contention that what one is afraid will occur, actually will occur. The feared outcome or consequence does not actually have to occur, rather, the evidence gives credence to the belief or prediction that it will.

From a clinical standpoint, the client is not responding to an object of fear; instead, to an internal symbolic representation of it, which (among other properties) has a compelling sense of reality. The client's behavioral expressions and coping strategies in turn are not a reaction to the feared object, but rather to the set of beliefs surrounding it, comprising the client's vision of what the feared object is, or might be. Under these circumstances, evidence is nothing more than the way things seem. One is "right to believe everything he believes as strongly as he believes it until it is rendered improbable by something else he believes" (Swinburne, 2011, p. 202). This support function often is conditional (Joyce, 2003). A conditional belief is one with the form

\footnotetext{
${ }^{2}$ In linguistics the study of how language actually is used is known as deixis (Brisard, 2011). Deixis is an example of how one's environment pragmatically imposes itself on one's beliefs. Although a word's semantic meaning may be fixed, what it actually means can vary with a number of factors, such as person, place and time. All of these are susceptible to ambiguous reference if viewed in isolation. It may not be clear, for example, who is designated by a pronoun. Spatial locutions such as "here" or "there" may designate more than one location, and temporal ones such as "now" and "then" might apply to different times (Corazza, 2011; Hanks, 2011). By constraining the limits of potential communication systems, ambiguity in natural languages actually may be adaptive (Piantadosi et al., 2012; Solé and Seoane, 2014). Deictic reference is a sub-category of indexical reference, which expands these principles to any context-sensitive use. Example: a vague expression with a hidden or latent variable, or one that has a particular meaning unique to a local community (such as "urban slang"), which often is uninterpretable absent specialized knowledge (Braun, 2007).
} 


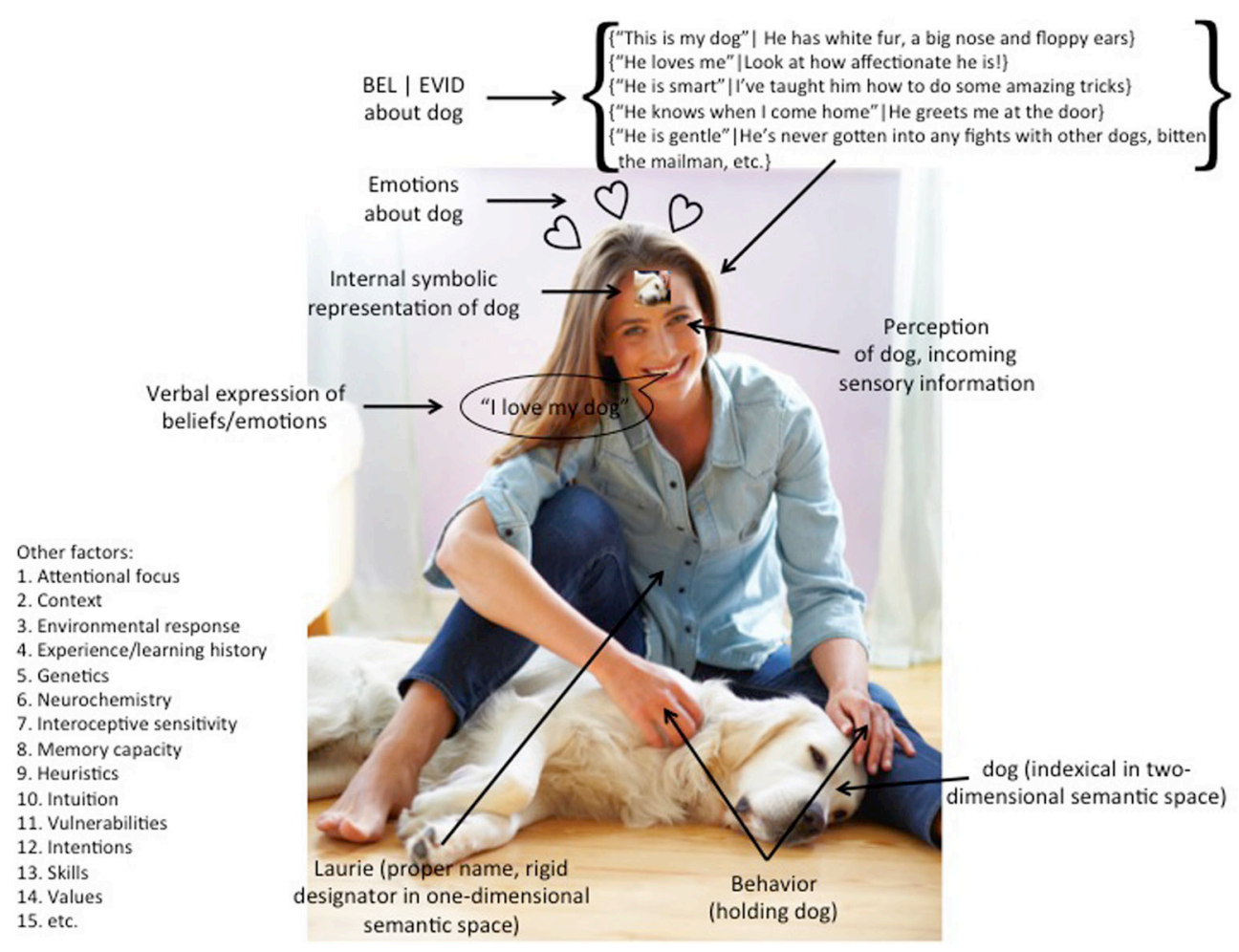

FIGURE 1 | Depiction of canonical belief model. Photograph licensed from Getty Images

$\operatorname{BEL}(x) \mid\left\{\mathrm{EVID}_{1}, \mathrm{EVID}_{2}, \ldots \mathrm{EVID}_{n}\right\}$, which reads "BEL(that “ $x$ ”) assuming $\left\{\mathrm{EVID}_{1}, \mathrm{EVID}_{2}, \ldots \mathrm{EVID}_{n}\right\}$ ” (Arlo-Costa, 2007).

In psychiatry, evidence often is clinical observations of patient behavior or patient reports of symptoms set forth in the Diagnostic and Statistical Manual (DSM-5) (American Psychiatric Association, 2013). An example of the former: BEL("This person is depressed") | EVID("She has insomnia or hypersomnia nearly every day and significant weight loss when not dieting or weight gain, or decrease or increase in appetite nearly every day"). An example of the latter: BEL("I'm depressed") | EVID("I have markedly diminished interest or pleasure in all, or almost all, activities most of the day, nearly every day; and I have feelings of worthlessness or excessive or inappropriate guilt nearly every day"). Evidence also can be third-person observations or patient reports of them. Example: EVID("She always is fighting with her friends") or EVID("My parents always told me so"). Persons also may have corollary beliefs about their beliefs (Paulus and Stein, 2010). For example, one might BEL(“Therapy/pharmacology doesn't help") or BEL("I'm going to have this for the rest of my life"). They also might be reflexive, as in BEL("I'm afraid of experiencing the symptoms of panic disorder").

\section{REFERENTIAL OPACITY}

A sentence's reference is what it designates. Sentences about beliefs are referentially "opaque" in that co-designating terms are not intersubstitutable (Quine, 1953/1980). To use a famous example, Oedipus married Jocasta; Oedipus believed Jocasta was his girlfriend; Oedipus didn't know Jocasta was his mother. This reads as follows: there was a time $\left(t_{1}\right)$ when Oedipus believed "Jocasta was his girlfriend" $\left(\mathrm{BEL}_{1}\right)$ given the supply of evidentiary data $\left\{\mathrm{EVID}_{1}, \mathrm{EVID}_{2}, \ldots \mathrm{EVID}_{n}\right\}$ then available to him. Even though true, Oedipus didn't believe at $t_{1}$ "Jocasta was his mother" $\left(\mathrm{BEL}_{2}\right)$, i.e., $\mathrm{BEL}_{2} \notin k_{1}$. He discovered this only at $t_{2}$, when (to his consternation) his knowledge base was $k_{2}$.

It follows that sentences about beliefs are informative in a way that "the sum of the angles of a triangle is $180^{\circ}$ " is not. Another famous example from Gottlob Frege: one believes the morning star rises in the east; one also believes the evening star sets in the west; one doesn't know both are the planet Venus. Even though both sentences refer to the same thing, their meanings or "senses" are different (Zalta, 2012). Failures of reference do not require one to postulate intentional conduct. They may be due to something as simple as accident or mistake (Austin, 1956/1970) ${ }^{3}$. The main

${ }^{3} \mathrm{~A}$ related concept is intensionality, later developed by Rudolf Carnap (1947/1988). Intension roughly is the same thing as meaning or sense. It contrasts with extension, which roughly is the same thing as reference. For Carnap, two phrases or sentences have the same extension if they designate the same thing, i.e. they both are true or false with regards to it, so that one can be substituted for the other. Intensional ones fail this test, at least for our actual world. There is, however, a possible world or state-description with different conditions, in which there is substitutability of identity. That possible world could be our actual world at a different point in time, or even the knowledge base of different persons. Beliefs, according to Carnap, are neither extensional or intensional, because one can believe $x$ but not $y$ or $z$ without realizing they 
problem with belief reports is that they rely on a client's interpretation of her subjective phenomenological experience (Dattilio et al., 2010).

\section{BELIEFS ARE SUBJECTIVE}

Referential opacity is a set-theoretical way of saying that beliefs are inherently subjective. As homo credens, people are infinitely capable of believing any number of different things (Shermer, 2012). One might believe in unicorns, global warming, conspiracy theories, that the sun revolves around the earth, or that they are the present King of France. It is not our intention to restrict the content of different beliefs, or the types of evidence that may be adduced to support them.

Psychiatrists and psychologists have devised numerous ways to find out what people believe, including observing them, testing them and asking them. In this sense, beliefs are "epistemically objective." Implausible as it may seem, in the near future, it might even be possible to read a person's mind using neurotechnologies such as fMRI (Harris et al., 2008; Poldrack et al., 2011); neuropsychiatric phenomics (Bilder et al., 2009a,b); connectionist-type principles (Sporns et al., 2005); or interactionist-type principles (Stumpf et al., 2008) ${ }^{4}$.

One of the perennial issues in cognitive science is whether these methods ever will be sufficient to account for belief's phenomenological texture. There is something unsatisfying about the neuromaterialistic/neurodeterministic program of extracting the substantive propositional content of a belief from neurological events. The reason why is because beliefs are underdetermined neurophysiologically; a single neurological state potentially could give rise to any number of different beliefs (they are "multiply realizable," (Levine, 1983, 1999); there is an "explanatory gap" between the two, Davidson, 1970, 1974). Further, they only can be held by the person who believes them. In this sense they are "ontologically subjective," as features or ascriptive predicates attributable only to that person (Dehaene, 2014, p. 9; Searle, 1995, pp. 7-9 $)^{5}$. From a clinical standpoint, there is no such thing as a standardized set of beliefs. Any approach to psychometric assessment that attempts to construct a taxonomy of typical beliefs, whether normative or pathological, most likely will not be successful, because beliefs fundamentally are distinctive, unique and personal. The clinician and the client must become

\footnotetext{
all refer to the same thing. Phrases or sentences are "intensionally isomorphic" if in fact this intersubstitutability relationship nonetheless exists.

${ }^{4}$ The Human Connectome Project was established in September, 2010 by the U.S. National Institutes of Health (Vance, 2010). In April, 2013, the U.S. announced its BRAIN Initiative, a $\$ 1$ billion connectionist-type project. It joined a similar $€ 1$ billion venture, the Human Brain Project, announced in January, 2013 by the E.U. (Abbott, 2013; Reardon, 2014). Internet companies such as the Allen Institute for Brain Science (Carey, 2012); Google (Markoff, 2012); and Vicarious (Albergotti, 2014) have similar objectives. Because connectionism results in something akin to a static, point-in-time wiring diagram, it is the opposite of non-linear dynamical psychiatry, see $\$ 4$. Connectionism has obvious applications to artificial intelligence (AI), beyond the scope of this review to investigate further.

${ }^{5}$ Eliminative materialists such as Churchland et al. necessarily are committed to a theory that psychological disorders are a result of brain malfunction, for example, defective or impaired neurochemistry (Matthews, 2013).
}

co-investigators to identify them and the evidence ostensibly supporting them.

\section{BELIEFS ARE MEDIATED AND MODERATED}

Beliefs are mediated and moderated by any number of different factors such as background, upbringing, life experiences, information processing strategies, temperament, attributional style, other beliefs, context, culture, motivation, and the presence of environmental cues and situational primes (Hope et al., 2010). They may be teleological or subject to confirmation bias. People deploy a variety of heuristic reasoning strategies to arrive at the beliefs they hold, including hypothesis formation, generalization and anomaly resolution. Reasoning has a rational basis rooted in probabilistic approaches to problem-solving (Kahneman and Tversky, 1979; Tversky and Kahneman, 1983; Oaksford and Chater, 2007). These strategies have evolved over time to facilitate our ability to make decisions in situations with incomplete information as to potential outcomes (Kahneman et al., 1982; Shafer and Tversky, 1985; Kahneman, 2003; Michalewicz and Fogel, 2004). They include everything from educated guesses to intuitive judgments and common sense. Induction is an important aspect of human reasoning (Heit and Rotello, 2010; JohnsonLaird, 2010), as are techniques to evaluate the evidence in support of individual beliefs such as Bayesian reasoning and DempsterShafer theory (Curley, 2007; Zhao and Osherson, 2010; Zhao et al., 2012). There also is a complex relationship between cognition and emotion (\$2.1.4, below; Pessoa, 2008, 2014). Beliefs are thought; emotions are felt. Just as one can have beliefs about one's emotions, so does one's emotional state affects one's beliefgenerating system. As with the subjective nature of beliefs $(\$ 1.3$, above), while all of these are controversial in various respects, it is not our intention to restrict the nature, scope and extent of potential belief influencers.

\section{CONDITIONS OF SATISFACTION}

A proposition has the property that it is true or false in the real world (McGrath, 2012). Beliefs, on the other hand, have conditions of satisfaction-what happens when things are the way one believes them to be. BEL("It's raining") is satisfied if in fact it is raining. Under those circumstances, we say the belief is "true." Beliefs have a "mind-to-world" direction of fit, in that the belief corresponds, to some extent, with reality (Searle, 1983).

\section{PSYCHOPATHOLOGY DISRUPTS THE ENTIRE BELIEF TEMPLATE}

One of the best ways to consider belief as a psychological construct is to examine counterfactual cases (Langdon and Connaughton, 2013). Persons who are anxious or depressed have beliefs that are dysfunctional and experienced as negative and invalidating (Bernstein et al., 2010, 2013). Example: BEL("If I try to do this, I'm going to fail").

The main problem with dysfunctional beliefs is they cannot be assigned a truth value, as in BEL ("The cat is on the mat" | There is a creature of the genus and species felis catus lying prone upon a rectangle of flooring material). Rather, one thinks conditions of satisfaction have been met, or thinks others think they have, when in fact they have not. Example: BEL("I'm a terrible person") does not imply one in fact is a terrible person (under some plausible 
consensus definition of what that means), or that others think so. Initially, negatively-valenced beliefs arise from misinterpretation of exteroceptive and interoceptive evidence and from information processing deficits (Paulus and Stein, 2010; Boden et al., 2012). Misevaluation of conditions of satisfaction then causes one to misjudge the evidence supporting the feared outcomes ("cost biases”) (Nelson et al., 2010a,b).

Normatively, we are inclined to impose certain minimum requirements on a set of beliefs in order to maximize the likelihood there will be a match between beliefs and conditions of satisfaction. These include conformity, conditioning and coherence (Howson, 2009).

\section{CONFORMITY}

Conformity disregards the substantive propositional content (" $x$ ") of BEL(" $x$ ") and requires only that one not endorse ("- $x$ ") simultaneously. Actual human reasoning might not be quite that simple. Research shows that people deal with inconsistencies not by attempting to refute one of the premises, but rather by trying to explain their origins, which has the side effect of revising their beliefs (Khemlani and Johnson-Laird, 2011).

\section{CONDITIONING}

Conditioning means that one should hold BEL(" $x$ ”) only for so long as $\left\{\mathrm{EVID}_{1}, \mathrm{EVID}_{2}, \ldots \mathrm{EVID}_{n}\right\}$ support $(x)$ and that one must update $(x)$ in light of new, incoming EVID. Such an update may involve modifications to the belief's conditions of satisfaction. Acquiring, maintaining and using new evidence in order to revise and update beliefs is a crucial human survival strategy (Patterson and Barbey, 2013). When incorrect or obsolete, conceptual knowledge must be repaired by integrating and explaining new material (Friedman and Forbus, 2011).

\section{COHERENCE}

Coherence means that only tautological falsehoods qualify for a probability assignment of $p(x=0)$ and only tautological truths qualify for $p(x=1)$. Thus one should not assign $p(\mathrm{BEL})=0$ to $\left(\mathrm{BEL}=\right.$ "the sum of the angles of a triangle is $180^{\circ}$ "), $\$ 1.2$, above. Rather, one should assign it $p(\mathrm{BEL})=1$.

Although they seem sensible, these axioms often do not apply to psychopathological states, because cognitive processing systems are impaired and emotion processing systems are dysregulated. Persons holding dysfunctional beliefs also may not be able to reason normatively. For example, they may disbelieve a set of propositions (e.g., evolution, global warming), which (most) everybody else believes (Perring, 2010). They may be indifferent to antecedent beliefs and stored knowledge; misunderstand inferential relationships; prioritize anomalous perceptual experiences; and lack a coherent theory of mind (Davies and Coltheart, 2000). It also makes sense to think of sentences expressing the ideations of persons with psychiatric disorders ( $\$ 1.2$, above) as ultra-opaque, thus even less amenable to substitutability of identity.

Their ability to evaluate evidence also may be impaired. Normatively, one relies on evidence to support a belief that what one thinks will occur, actually does occur. The evidence does not contradict, and in fact supports, the belief. In problematic cases, though, one does not have to believe a feared outcome or consequence actually will occur. Rather, all one has to believe is that the evidence supports the belief that it will, regardless of whether it happens or not (Joyce, 2011; $\$ 1.1$, above). In such cases, the evidence supporting the belief is misaligned with reality (Warman et al., 2007; Möller, 2012). Clearly this is a slippery slope. If people can believe whatever they want, then what's to stop them, particularly if they have a mental disorder?

\section{SUBJECTIVE PROBABILITY THEORY}

There are two modern epistemic interpretations of probability, which are logicism and subjectivism (Galavotti, 2011). Logicism contends that probability is a person-independent, normative relationship between real-world facts or events. Subjectivism is the theory that probability is one's degrees of belief (Hájek, 2011). Under the logicist interpretation, a tautological statement (such as $A \rightarrow B ; A ; \therefore B$ ) is certain regardless of what people may think about it. Its probability $p$ within a sample space $\Omega$ is 1 and in principle a large number of other beliefs can be incorporated within $\Omega$ so long as they are complementary ( $\$ 1.6 .3$, above). Under the subjectivist interpretation, different persons can believe whatever they want and assign their beliefs different $p$-values, even given the same evidence, permitting wide intersubjective belief variation.

Subjectivism almost certainly is true when considering a person's individual beliefs ( $\$ 1.3$, above). It breaks down, however, when considering a set comprising different beliefs, all held by the same person. This surely is normative. It would be odd for a person only to have one belief. Most people probably hold tens of thousands, perhaps hundreds of thousands, of beliefs, and their knowledge base most likely expands over time (Ohlsson, 2011, p. 293). The problem is not about subjectivism. Rather, it is about probability. Probability assessments do not occur on an interval scale, making it impossible to combine them or determine something analogous to their "mean" probability function using a linear pooling methodology (Wallsten et al., 1997) ${ }^{6}$. Beliefs comprising belief sets are interdependent, not independent. As a result, they cannot be evaluated using a differential equation or structural equation modeling approach. A differential equation approach will not work, because one cannot parameterize the values of the variables in order to create a belief change trajectory or phase portrait within a vector field. A structural equation modeling approach will not work, because one needs dimensionality reduction. For example, if one holds 13 separate beliefs, the binominal coefficient is 715 . Their interaction effects are 13! (13 factorial), or 6,227,020,800. Beliefs simply cannot be converted into numbers. They are not variables with values. Consequently, there must be some other way to fit beliefs into a non-linear dynamical model.

\section{BELIEFS HAVE SEMANTIC, PROPOSITIONAL CONTENT}

The solution is that beliefs have semantic, propositional content. Semantic content need not be expressed in complete sentences or

\footnotetext{
${ }^{6}$ Primarily for this reason, it is not clear that a comprehensive Bayesian approach to belief formulation and revision (for a summary, see Davies and Egan, 2013) is viable.
} 
even phrases. It can be concepts that either are the semantic content or that combine to form it (Laurence and Margolis, 2012). Beliefs are just such a conceptual state. Unlike variables populated by values, they must be elicited using a natural language and then comprised into sets at various stages of the belief generating process $\left(t_{1}, t_{2}, \ldots t_{n}\right)$. One selects beliefs and includes them as members of belief sets by promoting or prioritizing them ahead of others, based on one's credences in the evidence supporting them, or levels of confidence in their conditions of satisfaction (\$1.5, above; Makinson, 2009; Dietrich and List, 2013). Credences are situated along a continuum ranging from complete certainty of falsehood (does not meet perceived conditions of satisfaction) to complete certainty of truth (meets perceived conditions of satisfaction), depending on the evidence (Joyce, 2009).

\section{Preference functions}

Individual beliefs are organized into sets by preference or ranking functions $(\gamma)$, which assess the occurrence or persistence of the belief (Spohn, 2009). In order to assign a preference function, one must adopt a theory of utility to determine what counts as a desirable (utility-maximizing) action; establish degrees of belief; rank preferences; and determine what evidence counts as confirming what beliefs (Johnson-Laird, 2010, 2013; Meacham and Weisberg, 2011). The higher a belief's preference function, the more likely it is to provide a basis for behavior (Segerberg et al., $2009)^{7}$. Following this compilation process, different belief sets then can be evaluated in order to determine the nature, scope and extent of belief revision, most likely by a human skilled in use of the language in which the beliefs are expressed ${ }^{8}$. It is likely that different beliefs impose contrasting and disparate semantic burdens, based on factors such as prevalence, complexity, and the number of inferences involved.

\section{Semantic encoding}

An example of a technique that has been devised to elicit beliefs is the articulated thoughts in simulated situations (ATSS) thinkaloud paradigm, initially developed by Davison et al. (Zanov and Davison, 2010). Computational semantics attempts to model key features of natural language processes such as word meaning, sentence meaning, pragmatic usage and background knowledge (Stone, 2014). Recent initiatives include WordNet (Princeton University, 2010); latent semantic analysis (LSA) (University of Colorado Boulder, 1998); and SNePS (SNePS. Research Group., 2013). WordNet is a lexical database that groups words into sets of distinct cognitive concepts. LSA evaluates word similarity by similarity of context of use. SNePS is a natural language knowledge representation and reasoning system. A SNePS sub-routine models belief revision to maintain conformity, conditioning and coherence $(\$ 1.6 .1, \$ 1.6 .2, \$ 1.6 .3$, above). It too requires both individual beliefs and their relationships to be semantically encoded. One of the research priorities of several of today's most prominent internet companies is to develop algorithms for natural language

\footnotetext{
${ }^{7}$ Other than noting its important function, it is beyond the scope of this review to assess $\gamma$ 's mechanism of action.

${ }^{8}$ Obviously this may be any type of language capable of performing this function.
}

recognition. Apple acquired Siri in April 2010 (Wortham, 2010); Facebook announced Graph Search in January 2013 (Sengupta, 2013); Google announced Hummingbird in September 2013 (Miller, 2013); Yahoo announced SkyPhrase in December 2013 (Goel, 2013); and in February 2014, Wolfram released software intended to answer natural language queries with real-world information as a kind of "computational knowledge-engine" potentially demonstrating a form of "machine intelligence" (Lecher, 2014). One of the main challenges of these initiatives will be to capture the numerous shades and nuances of meanings used by fluent language speakers-the senses of words, in Fregean terms (\$1.2, above).

\section{Semantic entailment}

Closely related are problems of semantic entailment, that is, when a phrase or sentence commits one to other associated concepts. A classic example: "Socrates lived in Greece" should be inferred from "Socrates lived in Athens." Words are organized into "semantic/associative neighborhoods within a larger network of words and links that bind the network together" (Nelson et al., 2013, p. 797); Schroeter (2012) characterizes it as a twodimensional semantic space comprising rules for assigning values to words and sentences. Specifying exactly what these neighborhoods and networks are is challenging, because (as with semantic encoding, \$1.8.2, above) it depends on acquiring paraphrases, lexical semantic relationships, and inferences in contexts such as question answering, information extraction and summarizationsimilar to the usages employed by a natural language speaker (Dagan et al., 2009).

\section{BELIEFS DO NOT EXIST IN ISOLATION}

As semantic entailment illustrates, beliefs are components of complex domains, knowledge sets and networks (Davidson, 1994/2005). The limits of certitude on the one hand and psychopathology on the other allow for a wide variety of different $\{$ BEL | EVID $\}$ (Huber, 2009). One has an extensive set of unspecific background beliefs, which are culturally sensitive and context-dependent. They are "encoded in our linguistic formulation of the problem" (Weisberg, 2011, p. 507). Activities such as data selection, acquisition and learning require constant revision to one's knowledge base. Belief formation is subject to the overwhelming intervention of human experience, chance events and real-world constraints (Oaksford and Chater, 2007).

Quine and Ullian (1978) refer to this as a "web of belief""The totality of our so-called knowledge or beliefs, from the most casual matters of geography and history to the profoundest laws of atomic physics or even of pure mathematics and logic, is a manmade fabric which impinges on experience only along the edges" (Quine, 1953/1980, p. 42). Another way to look at beliefs is how they fit into what Searle (1995) calls the "background"-"all of those abilities, capacities, dispositions, ways of doing things and general know-how that enable us to carry out our intentions and apply our intentional states generally" (Searle, 2010, p. 31); or, the "foundational, non-representational non-rule-governed, dispositional structure of everyday understanding that underpins both our perception and our reasoning" (Rhodes and Gipps, 2008, p. 295). 


\section{DYNAMICS OF NATURAL LANGUAGE FORMATION}

Another important factor involved in belief semantics is the dynamics of natural language formation. Any language must have certain minimal constructs and features. These include generativity (one can create an indefinite number of new sentences from its component elements); discreteness (semantic elements, such as words, retain their identity, even in different syntactical contexts); compositionality (smaller language units, such as words, can be combined to form more complex ones, such as sentences); predictability; and recursion (phrases can be embedded within phrases to create new sentences) (Hauser et al., 2002; Studdert-Kennedy, 2005; Searle, 2007). Noam Chomsky famously theorized there was a universal human linguistic structure, which he called "generative grammar" (Chomsky, 1955, 1965). For Chomsky, syntax was the essential component of language, as opposed to semantics (meaning and reference) and pragmatics (how language actually is used) (Chomsky, 1977) ${ }^{9}$.

\section{LANGUAGE AND MIND}

It is beyond the scope of this review to investigate the complex relationships between language and mind (for a current overview, see Gleitman and Papafragou, 2012, 2013). Issues include criticism of Chomsky's views; whether logical variables represent the propositional contents of mental states and that cognition consists in manipulating them, a view most closely associated with Jerry Fodor (1975); criticism of Fodor's views; the linguistic relativity hypothesis (Swoyer, 2003); whether one can observe thoughts or emotions without labeling them (Linehan, 1993); or whether simply changing the way one labels them is effective to initiate cognitive/affective/behavioral change (Lieberman et al., 2007; Hayes et al., 2012). Our concern is not just a matter of choosing new words to describe beliefs, but rather reformulating beliefs, which then are expressed using words. At a minimum, we are in accord with Davidson (1975), who holds that belief is central to thought and that to have a belief requires the ability to express it using words ${ }^{10}$.

The substantive propositional content of an individual belief is interesting and important, particularly for determining just which dysfunctional beliefs typically align with different types of psychopathology. We are more interested, though, in the relationship of an individual belief to the other constituents of the belief set of which the individual belief is a member, and how that set's membership changes or is reformulated between $t_{1}$ and $t_{n}$. Belief revision does not involve alteration or replacement of that which the belief is about, i.e., the " $x$ " in BEL(that " $x$ "). It is not a form of

\footnotetext{
${ }^{9}$ The logical underpinnings of natural languages is an involved subject, beyond the scope of this review; for recent discussions, see Carruthers (2012) and Scholz (2011). Culbertson and Adger (2014) recently concluded that some grammatical rules (such as placing adjectives closest to the noun they modify) are innate.

${ }^{10}$ Davidson also contends that one must be aware one has a belief in order to hold it to begin with, because if one didn't, then one wouldn't be able to change it, because one wouldn't be able to recognize that the underlying belief was false. This type of metacognitive awareness might be helpful for eliciting beliefs, \$1.8.2, above. However, we concur with Laurence and Margolis (2012) that such a requirement overstates the case.
}

reality modification. Rather, the focus of change is belief considered as a propositional attitude ( $\$ 1$, above). The nature, scope and extent of belief revision only can be evaluated by inspecting modifications to the semantics of sets of $\{$ BEL $\mid$ EVID $\}$ at $k_{1}$ and $k_{n}$.

\section{INTEGRATING BELIEF INTO A NON-LINEAR DYNAMICAL SYSTEM}

Given these complex conditions, how can belief revision using CBT be integrated into a theory of non-linear, dynamical systems? As set forth at our Introduction, above, belief revision essentially involves two separate pathways: one through cognition, the other through behavior. CBT straightforwardly uses interventions directed toward both. The first, cognitive restructuring, requires belief revision in order to initiate behavioral change. The second, exposure/response prevention, requires behavioral change in order to initiate belief revision. Both cognitive restructuring and exposure/response prevention are mechanisms of belief revision from $k_{1}$ to $k_{2}\left(k_{1} \Delta k_{2}\right)$. Figure 2 illustrates their respective critical paths for a client presenting with borderline personality disorder, DSM-5 $\$ 301.83$.

\section{COGNITIVE RESTRUCTURING}

Cognitive restructuring is the therapeutic technology underlying the "cognitive" component of CBT (Spiegler and Guevremont, 2009). It contends that belief revision is the active ingredient motivating behavioral change: if belief set $k_{1}$ at time $t_{1}$ is modified to belief set $k_{n}$ at time $t_{n}$, then more adaptive behavior will follow (Leahy, 2001, p. 23). Cognitive restructuring erodes dysfunctional beliefs through several steps: (1) identify them; (2) marshal disconfirming evidence against them; (3) deconstruct them by challenging and refuting them; (4) replace them with alternative, more functional beliefs; and then (5) conduct behavioral experiments to see how the environment responds (Huppert, 2009; McMillan and Lee, 2010; Morina et al., 2011). Examples of cognitive-oriented interventions include decatastrophizing, disputing the evidence, detecting logical errors, chain analysis, situational analysis, etc. (Leahy and Rego, 2012).

Clinical interventions look something like these: If one is afraid of snakes, that belief can be challenged through a series of counter-examples. A herpetologist might be concerned with the snake's various anatomical features. A veterinarian might be concerned with its health. A herpetoculturist might be concerned with its taxonomy. Some people have them as pets, or pose with them for photographs, or perform with them in theatrical productions. Each of these persons has a different, proactive mental stance toward things that are (or that appear to be) snakes, none of which are threatening. Or, if a person with lived experience concedes suicidal ideations or reports parasuicidal target behavior, then one way to interrupt her might be to evaluate the evidence and establish the active ingredients of a life worth living: "We have no reliable information that persons who are dead have a better quality of life than persons who are alive. If you're dead, then therapy won't work and you won't be able to get better."

It follows that in order to recalibrate one's belief-generating system, one must modify one's credences in the evidence supporting the pathological belief. The first step in cognitive restructuring is to elicit $\operatorname{BEL}(x)$. Then, for example, $\mathrm{BEL}^{\ominus}$ ("I'm afraid of $\left.x^{\prime \prime}\right)$ at $t_{1}$ might get cognitively restructured into something 


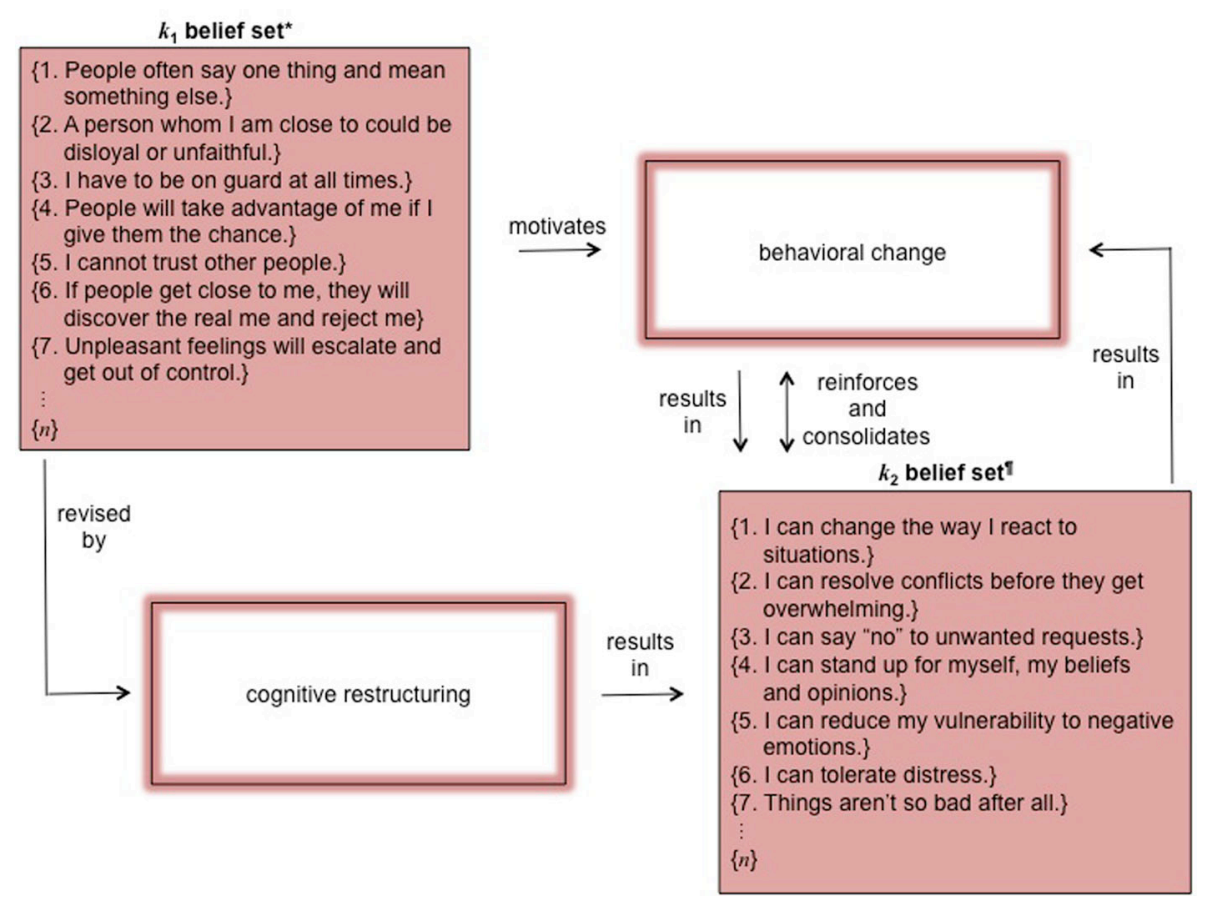

FIGURE 2 | Schematic of non-linear dynamical belief revision processes in CBT. *Adapted from Bahr et al., 2008. "Adapted from Linehan, 1993. $k_{1}$ is one's knowledge base at time $t_{1} ; k_{2}$, at $t_{2}$; this example uses beliefs characteristic for a person presenting with symptoms consistent with a diagnosis of borderline personality disorder. like $\mathrm{BEL}^{\oplus}$ (“There've been times when I've encountered $x$ and it wasn't so bad") at $t_{2}$. Positive belief attributions $\left(\mathrm{BEL}^{\oplus}\right)$ supplant negative ones $\left(\mathrm{BEL}^{\ominus}\right)$. Following cognitive restructuring, one then searches for discrepant evidence to confirm $\mathrm{BEL}^{\oplus}$ and disconfirm $\mathrm{BEL}^{\ominus}$, giving one a good reason to reformulate one's behavioral repertoire (Garland et al., 2010; Morina et al., 2011; Lightsey et al., 2012). Like belief, fear simply is another propositional attitude, i.e., $\{$ fear $(x) \mid$ EVID $\}$. Once one has accumulated enough relevant evidence, the choice clearly is framed: spend a significant portion of one's time entrained to the feared outcome, vs. the likelihood it actually will occur (i.e., conditions of satisfaction will be met, $\$ 1.5$, above). From an assessment standpoint, this likely would require one to have good metacognitive awareness, that is, the ability to reflect upon, understand and control their learning (Schraw and Dennison, 1994) in order to be able to identify and articulate their beliefs. A related concept from attachment theory is that of reflective functioning, that is, the ability to observe and describe one's own mental state (Fonagy et al., 1991).

Cognitive restructuring presents several issues:

1. It is difficult to challenge entrenched beliefs, even when they result in target behavior. Although maladaptive, to some extent they relieve immediate personal distress. Over time they are reinforced and become a conditioned response to the circumstances triggering them, which consolidate around their utility and effectiveness (Hartley and Phelps, 2012).

Example: aerophobia (fear of flying). In effect one has become fear-conditioned: the unconditioned stimulus (flying) initially provokes anxiety (unconditioned response), then becomes paired or associated with other typically-innocuous contexts or situations extrapolated from or analogized to the original one (such as acrophobia, fear of heights, the conditioned stimulus) (Samanez-Larkin et al., 2008). The resulting thought-pathways become ingrained with experience as they are reinforced by sufficient confirming evidence that maintains the associated beliefs until they become conditioned, learned responses (Tryon and McKay, 2009). One keeps doing the same thing over and over again because one is afraid of the perceived consequences of doing anything else.

2. Cognitive restructuring readily can morph into a form of escape/avoidance, if misapplied, because it feeds into intellectualization rather than the emotional, felt experience of a genuinely feared outcome. From a clinical perspective, too much thinking can become therapy-interfering, because one might approach the feared outcome as a puzzle to be solved. If this happens, then cognitive restructuring might backfire and one's tolerance of the feared outcome deteriorates even further. Feelings and thoughts both are in continuous competition for the same cognitive resources.

3. Because it involves a series of complex mental events, cognitive restructuring may be too complicated for many persons, especially those presenting with delusional features or severely dysregulated emotions ( $\$ 4$, below). They barely may be able to tolerate their dysfunctional beliefs, much less generate new ones. Persons with body dysmorphic disorder (BDD), for example, have a granular information processing style so they recall selective details of their appearance, rather than larger organizational design features (Feusner et al., 2007). 
This makes it difficult for them to generalize from a specific exposure addressing a particular feared outcome to more global cognitive change. While one might become inoculated or desensitized to a particular trigger, establishing it also applies in other contexts requires deducing there is a more pervasive relationship between them-which is a cognitive process. In effect one must blunt the impulse toward fractalization.

If one adopts the wrong cognitive hypothesis, then it will be ineffective to revise the associated belief set. In order to be successful, cognitive restructuring must correctly identify the ultimate fear: "I'll lose control," "I'll be judged," "I'll be embarrassed and humiliated," "I'm going to die," etc. If one is afraid of physiological symptoms such as those characteristic of panic, then the question should be, what happens next? For example, if a client presents with symptoms consistent with a diagnosis of social anxiety disorder (SAD), such as vasodilation (blushing), then the consequence might be that "people think I'm an idiot." If people think one's an idiot, then the next consequence might be "I'll be rejected and abandoned." If one's rejected and abandoned, then the next consequence might be "I'll lose my job and my relationships", etc. If the terminal fear is not adequately specified, then target behavior actually might increase over baseline, because rather than contending with dysfunctional beliefs, one just has animated or enlivened them. The reason why is because one thinks one has handled the problem, but one really hasn't ( $\$ 1.6$, above). One just has deferred dealing with it. As a result, further triggers will continue to recruit and redeploy cognitive, affective and physiological assets to support it (Smits et al., 2008; Olthuis et al., 2012).

4. Cognitive restructuring essentially is a process of "out with the old, in with the new" using interventions such as those described at \$2.1, above (Leahy and Rego, 2012). Because CBT regards dysfunctional beliefs as distortions or errors in thinking, such a challenge might be experienced as emotionally invalidating (Leahy, 2001, p. 58; Linehan, 1993, p. 92). Familiar (and to some extent serviceable) beliefs may be revealed as unrealistic, mistaken, distorted, or even irrational. As a result, subsequent behavior might just exchange one cognitive/affective state (e.g., anxiety) for another (e.g., "I'm deficient" or "I'm defective"). In this respect, dialectical behavior therapy (DBT) augments CBT case conceptualization. It emphasizes emotional validation in addition to cognitive restructuring. It is not enough to focus only on beliefs and behavior, because emotions (and their associated interoceptive sensations) also are an integral component of the same equation. In fact, if anything, in a contest between emotions and cognitions, emotions most likely will win out, because they are more fundamental and, in a sense, primordial (LeDoux, 1996; Damasio, 1999; Afraimovich et al., 2011; Frazzetto, 2013). A recent study by Moser et al. (2014) concluded that positively reinterpreting negative emotional experiences (such as those associated with fearful outcomes) is one of belief revision's key mechanisms, with well-defined neurological correlates. The equation should read: $\{$ dysfunctional beliefs $\}+\{$ emotional

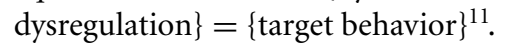

5. CBT uses phrases such as "downward arrow technique" (Persons et al., 2006) and "chain analysis" (Lynch et al., 2006) as metaphors for complex cognitive processes, without considering their component elements. This leaves beliefs in a kind of mysterious "black box"-something everyone knows must be addressed, but without unpacking their underlying logic and structure. What CBT lacks (and what we offer) is a theory of belief revision-which beliefs get changed, why those instead of others, and what the constraints are.

6. Cognitive therapy is a means to behavioral change, not an end in and of itself. During cognitive restructuring, one develops hypotheses that exposure/response prevention either will falsify or prove. For example, if a person with SAD undergoes cognitive therapy and concludes, "Well, I guess it's not so bad if I speak up at meetings," but then never does so, cognitive restructuring will not have been effective.

\section{EXPOSURE/RESPONSE PREVENTION}

CBT's second critical path is behavioral intervention based around the concept of progressive desensitizationexposure/response prevention to a feared outcome, rather than escape/avoidance of it. It proposes that the main driver for therapeutic change is behavior, not cognition. It assumes that it is difficult for cognition alone to motivate new behavior; that one of the main reasons why persons engage in target behavior is to attempt to induce their environment to respond; that when reinforcement contingencies are altered, behavioral modification follows; and that psychological change occurs as a result. Instead of being the driving force motivating behavioral change, cognition brings up the rear. This dichotomy is similar to that between thought and action, or thinking vs. doing.

Using this approach, the first question always must be "how did the behavior get to be the way that it is." Often this can be explained using classical and operant conditioning paradigms. Sometimes people enact coping strategies to prevent something bad from happening; occasionally, it may even be pleasurable. If, however, actions have not had effects, then it is necessary to supply them in order to consequate that behavior. The next step is to unpair or decouple a conditioned stimulus from an unconditioned one, or to extinguish target behavior that previously has been reinforced (and the entire cycle giving rise to it), by establishing prospective environmental contingencies; acquiring skills; enacting new behavior; and then evaluating evidence as to how the environment responds (Spiegler and Guevremont, 2009). At each stage, behavioral markers demonstrate that the feared outcome did not occur.

Target behavior typically is a form of escape/avoidance. It may be accommodating and protective in the short term, because it reduces the threat posed by dysfunctional beliefs $(\$ 2.1 .1$, above;

\footnotetext{
${ }^{11}$ While we spend considerable time analyzing pathways between cognition and behavior ( $\$ 4$ ), it is beyond the scope of this review to expand our analysis to include emotions and affect. For speculation on this point, see (Afraimovich et al., 2011; Huntsinger and Schnall, 2013); and (Rabinovich et al., 2010a).
} 
Hofer, 2010). However, it is ineffective over the long term, as novel and even more threatening stimuli arise in the world and present for interpretation and action (Roemer et al., 2002; Carter et al., 2008; Lee et al., 2010). It does not affect one's pre-existing vulnerabilities and the environmental affordances that trigger or activate them. It does not down-regulate dysfunctional beliefs or dysregulated emotions. Instead, by impeding assimilation of accurate information, it maintains judgmental biases, emotional vulnerability and alarm sensitivity-a kind of "contrast avoidance" (Taylor and Alden, 2010; Newman and Llera, 2011, p. 226).

Adaptive new behavior, on the other hand, is generated by stepwise exposure followed by systematic desensitization or response prevention. Initially this is a "fragile behavioral state" and can be recovered "spontaneously or subsequent to environment influences, such as context changes or stress" (Herry et al., 2010, p. 599). As one confronts the feared stimulus, the fear becomes extinguished through a reverse inhibitory learning process, allowing for more flexible control of conditioned response by forming a consolidated extinction memory. With continued or reinitiated exposure, post-behavior cognitions consolidate and become further refined, dampening responsiveness in the brain's fear-sensitive network (Hauner et al., 2012; Trouche et al., 2013). Similar to cognitive restructuring $(\$ 2.1 .3$, above), in order to be an effective intervention, exposure/response prevention must be autogenic, i.e., personalized more or less exactly to falsifying or validating a specific feared outcome-the one that matters the most.

Example: if one is afraid of heights and things that move quickly, then an escape/avoidance strategy would be not to engage with them. An exposure/response prevention strategy, on the other hand, would be to take opposite action by (say) going on a series of roller-coaster rides at an amusement park, starting with those that are small and innocuous but then building up over the course of a day to those that are taller and faster. At each step one take's stock of one's mental condition, notices that one still is alive and breathing, thereby habituating or acclimating oneself to more challenging stimuli, resulting in cognitive change. Example: if one is afraid of driving on the freeway, then an escape/avoidance strategy would be to take surface streets. What happens, though, if the surface streets all are blocked and the only way to get to one's destination is by taking the freeway? The escape/avoidance strategy no longer works. A more adaptive exposure/response prevention strategy would be to progressively expose oneself to driving on the freeway by (say) traveling from one on-ramp to one off-ramp at a time, then gradually building this up to two, then three, etc. Example: rather than engaging in a difficult and potentially futile process of weighing pros and cons in order to motivate herself not to drink alcohol, a person with substance over-use issues alters her behavioral regimen not to drive by liquor stores and restructures her social network to exclude those persons maintaining it.

Behavior modification is powerful. Some theorists contend that in a contest between beliefs and behavior (i.e., cognitive restructuring versus exposure/response prevention followed by belief consolidation), behavior always will win; see e.g., Gipps (2013) and Longmore and Worrell (2007). Historically, committed behaviorists denied one has beliefs to begin with; rather, one only is disposed to respond to stimuli (Pavlov, 1927/2003;
Skinner, 1947; Ryle, 1949/2009). Today, along similar lines, eliminative materialists such as Churchland and Churchland (1998) and Dennett (1992) deny beliefs are anything more than folkpsychological explanations (this phrase is intended to be mildly derisive) of complex neurological events (Bickle et al., 2010). The weakness of this formulation is what originally lead to the cognitive revolution, as exemplified, for example, by Chomsky's (1959) critique of Skinner's (1957/1991) Verbal Behavior. Behavior does not, however, occur in a vacuum. There must be some threshold level of belief revision in order to stimulate it, most likely based on the salience of an initial belief or belief set, its relevance to current goals, or its resonance with a particular feature of the environment. In principle this should be similar to the way that intention redirects attention from the default mode network to some other neural construct or constructs (Buckner et al., 2008; Rabinovich et al., 2012a). Attention focuses intentional orientedness, causing heightened self-monitoring, resulting in greater interoceptive sensitivity (Simmons et al., 2006; Woody and Nosen, 2009), one of the main precursors to belief change.

Thereafter, the role of cognition primarily is to consolidate revised beliefs and build behavioral insight. Beliefs are conjectures or predictions about conditions of satisfaction and the evidence supporting them. The only way to accumulate evidence is by enacting behavioral experiments and seeing what happens. From a clinical standpoint, the client can assume the role of an anthropologist, investigating the behavior of a strange tribe, of which she also happens to be a member. If there is insufficient evidence to support a belief, or the evidence disconfirms it, then there is no particular reason why it should be retained as a component element of a belief set. Discrepant evidence creates "expectation violations" (disconfirms pathogenic beliefs), modifying behavioral vectors previously directed toward averting feared outcomes, thereby raising the cognitive accessibility of alternative and more flexible belief formulations. In many instances, the cognitive objective is not to eradicate fear, but rather to tolerate ambiguity. Using a variation of the Rescorla and Wagner (1972) model, Craske et al. (2012) recently advocated that while it may become semi-perturbed, the pairing or coupling between the conditioned stimulus and the unconditioned stimulus never really is eradicated. Instead, it is inhibited or attenuated. It follows that variability in fear level, or reintroducing elements of the unconditioned stimulus concurrently with the conditioned stimulus during exposure, is more likely to create a durable learning experience. Doing so maximally violates expectations, eliciting more improvisational and extemporaneous behavior, thereby promoting belief revision (Kircanski et al., 2012). The goal is not so much extinction (from a behavioral standpoint) as it is acceptance (from a cognitive standpoint) which is a completely different skill. As the Viennese novelist (and, in retrospect, proto-ACT theorist) Robert Musil (1930-43) declared: "one must live with uncertainty, yet not be caught in hesitation."

Cognition also extrapolates or pluralizes revised beliefs to analogous contexts. When one masters a skill in a certain domain, that mastery experience carries over to others. Only the target behavior will be affected without generalization effects. While this may be acceptable insofar as it goes, especially in refractory cases, 
exposure/response prevention will have limited success unless it also addresses adjacent beliefs (Arntz, 2002; Bryant et al., 2003). To continue with the example from $\$ 2.1 .6$, above, if a person with SAD starts mindlessly speaking up at meetings, that will not in and of itself change cognition. It simply is a form of unregulated exposure/response prevention. It may even become a form of escape/avoidance if she engages in it unthinkingly in order to avoid cognitive dissonance, a necessary precursor to extinction. The more that target behavior is effective as a form of escape/avoidance, the more difficult it will be to create a counteracting exposure/response prevention, precipitating belief revision. Reciprocally, some persons who hold severely dysfunctional beliefs or who are considerably emotionally dysregulated may lack the cognitive capacity to perform generalization operations $(\$ 4$, below). In such cases, target behavior must be specified even more precisely, otherwise it will not be extinguished, or some other undesired behavior will be reinforced instead.

\section{AUTOMATIC NEGATIVE THOUGHTS, INTERMEDIATE BELIEFS, CORE BELIEFS}

How do cognitive restructuring and exposure/response prevention integrate with the epistemology of CBT? Received BeckEllis theory (Ellis, 1994; Beck, 2011) holds that doxastic agents have a hierarchy of automatic thoughts, intermediate beliefs and core beliefs. There now are several dozen recognized schools of CBT, all of which trace their provenance back to Beck and Ellis (Emmelkamp et al., 2010).

\section{Automatic thoughts}

For Beck (2011), automatic thoughts are an undercurrent of cognitions and self-talk, subject to articulation on query or in response to an analogous simulation (Zanov and Davison, 2010). They rarely are conscious in the sense of a state one is aware of, however they typically are accessible and available to other cognitive processes (van Gulick, 2004).

\section{Intermediate beliefs}

Automatic thoughts are linked to core beliefs by intermediate beliefs. Beck (2011) assumes the role played by intermediate beliefs is unproblematic (p. 205), however they can be difficult to formulate and it is not clear anybody ever has held an intermediate belief. In principle they should be rules or assumptions in the form of conditional if-then statements such as: "If I (engage in rigid behavioral coping pattern), then (I'll be insulated from a core belief I'll experience as aversive)" or "Unless I (engage in rigid behavioral coping pattern), then (I'll be exposed to a core belief I'll experience as aversive)." For example, if one unexpectedly is running late for work because the bus is running late, intermediate beliefs might be: "If I'm always on time for meetings, then I'm not inadequate" (or, "Unless I'm always on time for meetings, then I'm inadequate"). They should not, however, be idiographic. Thus, "If I'm on time for meetings, then I'll do well at work" is not a proper formulation of an intermediate belief. Rather, it is more of an expression of a particular coping style, connecting to an individual instance of behavior, not a pattern of behavior. Nor should intermediate beliefs be depersonalized. Thus, "People who frequently are late for meetings typically end up losing their jobs" also is not a proper formulation of an intermediate belief, because the outcome does not tie to a more generalizable core belief.

\section{Core beliefs}

A core belief is not an actual thought in an epistemological sense. E.g., if the automatic thought is "I'm running out of money," then the associated core belief might be, "One needs a lot of money in order to be safe," even though one never actually thinks that particular core belief. Uncovering it is cognitive restructuring's raison d'être. It is tempting to think of a core belief as an implicit conclusion derived from the application of a rule (an intermediate belief) to a premise (an automatic thought). All three are components of an information processing system (Beck, 2011, p. 33) or a way for people to "organize their experience in a coherent way in order to function adaptively" (Beck, 2011, p. 35).

Still, it is not clear what comprises a set of core beliefs. Is it just a single belief, or a set of multiple, interdependent beliefs? Although they acknowledge the possibility that there are many of them, all of the Beck-Ellis examples treat beliefs as singletons rather than as elements of belief sets. It seems implausible that individual beliefs, regardless of how entrenched, proximately cause (or explain) a complex phenomenon such as human behavior. It seems more likely that human behavior is the outcome of a dynamic, interactive network of beliefs (and that it reciprocally influences them).

It also is unclear just what causes what. Does a triggera real-world or imaginal event-activate core beliefs or automatic thoughts? Once set in motion, which causes which? Beck (2011) has little to say about the relationships between automatic thoughts, intermediate beliefs and core beliefs other than core beliefs "activate" automatic thoughts (p. 32) and "underlie" (p. 36) both them and intermediate beliefs. Intermediate beliefs "influence" one's view of the situation or event (p. 35), which "trigger" automatic thoughts (p. 38) (Beck apparently views these different verb formulations as synonymous).

\section{BELIEF REVISION-THREE AND ONLY THREE FUNDAMENTAL SYNTACTICAL OPERATIONS}

While CBT provides useful tools that can be used to induce or facilitate belief revision such as cognitive restructuring or exposure/response prevention, the problems with Beck's (2011) formulation ( $\$ 2.3$, above) make clear that it comes up short to explain just how they do so. At best, from a clinical standpoint, they just "soften" a set of dysfunctional beliefs, or point out why individual beliefs are implausible (Beck) or illogical (Ellis). We contend that the process of belief revision in CBT can be better characterized using $\mathrm{AGM}^{12}$.

\footnotetext{
${ }^{12}$ Since their original (1985) paper, AGM theory has evolved and undergone significant further developments (Makinson, 2003; Costa and Pedersen, 2011; Gärdenfors, 2011). While there are other theories of belief revision (Fermé and Hansson, 2011), AGM is the one that has acquired the most traction in the literature. The concept of $k$, whether and how BEL represents or stands for a psychological state, all of the AGM postulates and all of the operations potentially performable on $k$ have been discussed and challenged extensively. It is beyond the scope of this review to analyze these various permutations.
} 
According to AGM, a person's knowledge base $k$ comprises a number of individual beliefs, $\mathrm{BEL}_{1}, \mathrm{BEL}_{2}, \ldots \mathrm{BEL}_{n}$, which combine together to form belief sets. AGM provides a set of ecological rules for how beliefs dynamically evolve by examining the interaction effect of $k_{1}$ 's and $k_{2}$ 's respective belief sets at equilibrium points $t_{1}$ and $t_{2}$ during the process of belief revision. The problem AGM is trying to solve is to minimize the set of $\mathrm{BEL}_{\text {new }} \in k_{2}$ and the set of $\mathrm{BEL}_{\mathrm{old}} \notin k_{1}$ simultaneously, so as to maximally preserve both $k_{1}$ 's and $k_{2}$ 's inductive cores. Unlike $k_{1}, k_{2}$ is less subjectively distressing and leads to more adaptive or normative behavior.

This is interesting and important because it defines the necessary and sufficient conditions for belief revision-what has to happen and that is all that has to happen. It therefore specifies the minimum requirements necessary for successful cognitive restructuring or belief modification following exposure/response prevention. From a clinical standpoint, maybe this is all one can expect, particularly with difficult cases. It can accommodate a diverse belief set, limited only by one's strategies to interpret beliefs, semantically encode them by assigning them substantive propositional content (that " $x$ ") and then identify the resulting doxastic commitments, which gives it explanatory power. It deemphasizes the distinction between automatic thoughts, intermediate beliefs and core beliefs. All beliefs are targets for revision at any equilibrium point. This better explains the subjective phenomenological experience of belief revision. It also recognizes there are different related beliefs at $t_{1}, t_{2}$, etc. Some motivate behavioral change, e.g., $k_{1}=$ ("If I enact behavioral experiment $y$ then $z$ will happen"). Others reinforce it, e.g., $k_{2}$ following skills acquisition or exposure/response prevention $=$ ("This is how the environment responded"). It is a dynamical system because it changes and evolves in real time. It is nonlinear because the " $x$ " of $\operatorname{BEL}(x)$ is idiographic, idiosyncratic and unpredictable.

During belief revision, elements of belief sets are modified or replaced using three (and only three) fundamental syntactical operations, which are expansion (EXP); revision (REV); and contraction (CON). Particular beliefs are the semantics this architecture supports (Fermé and Hansson, 2011).

\section{EXPANSION (EXP)}

EXP is like adding a new belief without deleting any old ones. EXP (expressed as $k_{1}+$ BEL $x$ ) occurs when one accepts, acknowledges or incorporates a $\mathrm{BEL}_{\text {new }}$ into $k_{1} \cdot k_{2}=\left(k_{1}+\mathrm{BEL}_{\text {new }}\right)$ : $\mathrm{BEL}_{\text {new }}$ is added to $k_{1}$; no $\exists\left(\mathrm{BEL} x \in k_{1}\right)$ is deleted or removed from $k_{1}$; and on conclusion of belief revision, $\left\{\left(\mathrm{BEL}_{1} \ldots \mathrm{BEL}_{\mathrm{n}}\right) \cup\right.$ $\left.\mathrm{BEL}_{\text {new }}\right\} \subseteq k_{2}$, with the caveat it also is the smallest possible set of $\left(k_{2} \cup \mathrm{BEL}_{\text {new }}\right)$. Although it might be, $\mathrm{BEL}_{\text {new }}$ does not necessarily have to be consistent with $k_{1}$. Since AGM does not restrict the substantive propositional content " $x$ " of $\mathrm{BEL}_{\text {new }}(\$ 1.3$, above), it can have either $\oplus$ or $\ominus$ valence. If it has $\oplus$ valence (BEL $\left.x^{\oplus}\right)$, then it contributes to cognitive restructuring at $t_{2}$. If it has $\ominus$ valence $\left(\operatorname{BEL} x^{\ominus}\right)$, then either it does not contribute to cognitive restructuring, or may even reinforce $k_{1}$.

For this reason, EXP might be confusing for an AGM agent. $\mathrm{BEL}_{\mathrm{old} \ominus}$ remain as elements of her belief set, even as they are joined by $\mathrm{BEL}_{\text {new }}$, which can either be $\mathrm{BEL}^{\oplus}, \mathrm{BEL}^{\ominus}$ or ambiguous. To continue with our previous example, the trigger is running late for a meeting at work because one's bus is late. Under such circumstances, one's beliefs might be: $\mathrm{BEL}_{1 \ominus}$ ("My boss is going to get angry"), BEL $2 \ominus$ ("My colleagues will disrespect me") and BEL $3 \ominus$ ("My opinion doesn't count"). One then acquires a new belief $B L_{4} \ominus$ ("I need this paycheck to support myself"). $\mathrm{BEL}_{4 \ominus}$ is not inconsistent with $\left\{\mathrm{BEL}_{1 \ominus}, \mathrm{BEL}_{2} \ominus, \mathrm{BEL}_{3 \ominus}\right\}$. For these reasons, we hypothesize that it is unlikely EXP alone will result in successful cognitive restructuring or belief consolidation following exposure/response prevention. Figure 3 depicts this outcome.

\section{REVISION (REV)}

REV is like adding a new belief and deleting old, inconsistent ones. As with EXP, REV (expressed as $k_{1}^{*}$ BEL $x$ ) occurs when one accepts a $\mathrm{BEL}_{\text {new }}$ or admits it to one's $k_{1}$ knowledge base. $k_{2}=\left(k_{1}+\mathrm{BEL}_{\text {new }}\right): \mathrm{BEL}_{\text {new }}$ is added to $k_{1}$; on conclusion, $\left\{\left(\mathrm{BEL}_{1} \ldots \mathrm{BEL}_{\mathrm{n}}\right) \cup \mathrm{BEL}_{\text {new }}\right\} \subseteq k_{2}$. The main difference between $\mathrm{REV}$ and EXP is that with REV, a BEL old must be deleted from $k_{1}$ so that $k_{2}$ is consistent with $k_{1}$.

\section{Pragmatic Closure}

$k$ is "logically closed" if it represents all of one's beliefs, even though they may be difficult or impossible to specify. Every BEL

\begin{tabular}{|c|c|c|}
\hline$\left\{k_{1}\right\} \mathrm{BEL}_{\text {old }}$ & $\Delta_{\text {bel }}$ & $\left\{k_{2}\right\} B E L_{\text {new }}$ \\
\hline $\begin{array}{l}\mathrm{BEL}_{1} \ominus=\text { "My boss is going } \\
\text { to get angry." }\end{array}$ & & $\begin{array}{l}\mathrm{BEL}_{1} \ominus=\text { "My boss is going to } \\
\text { get angry." }\end{array}$ \\
\hline $\begin{array}{l}\mathrm{BEL}_{2}{ }^{\ominus}=\text { "My colleagues } \\
\text { will disrespect me." }\end{array}$ & & $\begin{array}{l}\mathrm{BEL}_{2}{ }^{\ominus}=\text { "My colleagues will } \\
\text { disrespect me." }\end{array}$ \\
\hline $\begin{array}{l}\mathrm{BEL}_{3}{ }^{\ominus}=\text { "My opinion } \\
\text { doesn't count." }\end{array}$ & & $\begin{array}{l}\mathrm{BEL}_{3}{ }^{\ominus}=\text { "My opinion doesn't } \\
\text { count." }\end{array}$ \\
\hline EXP & $\begin{array}{l}\mathrm{BEL}_{4}{ }^{\ominus}=\text { "I need this } \\
\text { paycheck to support myself." }\end{array}$ & $\begin{array}{l}\mathrm{BEL}_{4}{ }^{\ominus}=\text { "I need this } \\
\text { paycheck to support myself." }\end{array}$ \\
\hline
\end{tabular}

FIGURE 3 | EXP. 
logically derivable from $k$ already $\in k$, i.e., $k$ includes not only BEL but also all BEL consequences. Stand-alone beliefs sometimes are referred to as "basic beliefs" and consequences as "derived beliefs"-those beliefs one is epistemically committed to hold, even though one might not actively do so (Gabbay et al., 2010). Since $k_{1}$ is logically closed in this sense, only one anomalous $\operatorname{BEL}(x)$ is sufficient to create inconsistency; an inconsistent $k(x)$ sometimes is notated as $k(x) \perp$. In this respect, REV incorporates the concept of conformity $(\$ 1.6 .1 \text {, above })^{13}$.

\section{Frame of discernment}

To some extent the problem of logical closure is solved by the concept of "frame of discernment." The domain of all possible beliefs must be truncated in order to engage in practical inference and reason from belief to action. One's frame of discernment is the set of all of the beliefs comprising $k$ that are useful to answer, in a practical context, the question of what one believes. It is notated $\Theta$ where (BEL $\in \Theta \in k$ ); we might say one's $\Theta$ is "pragmatically closed" in order for one to be able to function effectively in the world. Example: when one adopts the set $\Theta_{1}=$ \{red, white, yellow $\}$ as the frame for the question "What color rose is Bill wearing today?" one formalizes the variable $x$ with those possible values. The frame $\Theta_{2}=\{$ white, blue $\}$ might answer the question "What color shirt is Bill wearing today?" The frame for the conjoined question "What color rose and what color shirt is Bill wearing today?" is $\Theta_{1} \times \Theta_{2}=\{$ (red, white), (red, blue), (white, white), (white, blue), (yellow, white), (yellow, blue)\} (Liu et al., 1991). Frame of discernment narrows

\footnotetext{
${ }^{13}$ There are several other possible operations one can perform using REV: "partial meet revision" and "transitively relational partial meet revision." We do not cover these, here. Logical closure may be unrealistic in a real-world environment, because one might not recognize derived beliefs, even if they are specified. One draws on numerous other beliefs, facts assumptions and knowledge about the world in order to function effectively within it. It is unlikely one ever is in command of all possibly relevant evidence pertaining to a belief or beliefs. It most likely would be impossible to specify fully all of the beliefs comprising one's knowledge base, a project that in effect would require axiomatizing all human knowledge (Dreyfus, 1992; Shanahan, 2009).
}

down a potentially unwieldy set of beliefs into something more pragmatically serviceable ${ }^{14}$.

To continue with our earlier example, let's say that at $k_{2}$ one has acquired $B E L_{\text {new }} \oplus$ ("The last time I was late for work, my boss was understanding”). Because it is $\mathrm{BEL}^{\oplus}$, it is inconsistent with $\left\{\mathrm{BEL}_{1 \ominus}, \mathrm{BEL}_{2} \ominus, \mathrm{BEL}_{3 \ominus}\right\}$. The objective of cognitive restructuring or belief consolidation following exposure/response prevention is for $k_{1}$ to be inconsistent with $k_{2}$. It follows that $\mathrm{BEL}_{\text {old }}$ should be $\mathrm{BEL}^{\ominus}$ and $\mathrm{BEL}_{\text {new }}$ should be $\mathrm{BEL}^{\oplus}$, otherwise, there would not be any therapeutic change. Cognitive restructuring is teleological in that it is undertaken with a specific objective in mind, which is belief change and resulting behavior modification. For these reasons, we hypothesize that REV is the paradigm case of successful cognitive restructuring (see Figure 4).

\section{CONTRACTION (CON)}

CON is like deleting an old belief without adding any new ones. CON (expressed as $k_{1} \div \mathrm{BEL} x$ ) is when one rejects a $\mathrm{BEL}_{\mathrm{old}}$ or deletes it from her knowledge base. $k_{2}=\left(k_{1}-\mathrm{BEL}_{\mathrm{old}}\right)$ : $k_{2}$ supersedes $k_{1} ; k_{2} \subseteq\left(k_{1} \mid k_{2} \nrightarrow \mathrm{BEL}_{\mathrm{old}}\right)$; but from which no (BEL $x \in k_{1}$ ) has been unnecessarily deleted. Because a BEL has been deleted from one's $k_{1}$ belief set, $\mathrm{CON}$ is a process of

\footnotetext{
${ }^{14} \mathrm{~A}$ related concept is partition dependence, which is the psychological pattern of how one divides up a set of possible outcomes into particular events. Doing so influences the perceived likelihood those events will occur. Combining events into a common partition lowers their perceived probability. Conversely, unpacking events into separate partitions increases their perceived probability (Sonnemann et al., 2013). For example, apocryphally, Eskimos have numerous words for "snow," because that phenomenon allegedly is far more prevalent where they live than elsewhere (Martin, 1986). They need a vocabulary with greater subtlety and nuance to describe its various aspects. This in turn increases the probability an event will be interpreted as snowlike, because a set of phenomena (e.g. cold wet stuff falling from the sky) with its associated beliefs (e.g. if you stay out in it too long, you will freeze) has been parsed out into separate partitions. Rabinovich et al. (2014, p. 1) recently characterized this as "chunking"-a dynamical strategy agents use to "perform information processing of long sequences by dividing them in shorter information items" thereby making "more efficient use of short-term memory by breaking up long strings of information."
}

\begin{tabular}{|c|c|c|}
\hline$\left\{k_{1}\right\} \mathrm{BEL}_{\text {old }}$ & $\Delta_{\text {bel }}$ & $\left\{k_{2}\right\} \mathrm{BEL}_{\text {new }}$ \\
\hline $\begin{array}{l}\mathrm{BEL}_{1} \ominus=\text { "My boss is going } \\
\text { to get angry." }\end{array}$ & & $\mathrm{BEL}_{1} \ominus=$ deleted. \\
\hline $\begin{array}{l}\mathrm{BEL}_{2} \ominus=\text { "My colleagues } \\
\text { will disrespect me." }\end{array}$ & & $\mathrm{BEL}_{2}{ }^{\ominus}=$ deleted. \\
\hline $\begin{array}{l}\mathrm{BEL}_{3} \ominus=\text { "My opinion } \\
\text { doesn't count." }\end{array}$ & & $\mathrm{BEL}_{3} \ominus=$ deleted. \\
\hline REV & $\begin{array}{l}\mathrm{BEL}_{4} \oplus=\text { "The last time I was } \\
\text { late for work, my boss was } \\
\text { understanding." }\end{array}$ & $\begin{array}{l}\mathrm{BEL}_{4^{\oplus}}=\text { "The last time I was } \\
\text { late for work, my boss was } \\
\text { understanding." }\end{array}$ \\
\hline
\end{tabular}

FIGURE 4 | REV. 
“epistemic entrenchment." In rejecting $\mathrm{BEL}_{\mathrm{old}}$, one also may have to disavow other BEL $x$ that imply or are implied by it. Which beliefs should be deleted? From the standpoint of CBT:

1. One should start with those beliefs that violate the requirements of conformity, conditioning and coherence (\$1.6.1, $\$ 1.6 .2, \$ 1.6 .3$, above). Because of coherence, BEL $x \notin k_{n}$ trivially is non-entrenched and tautologies are fully entrenched.

2. Next, since an AGM agent strives for minimal change and maximum information value, she should relinquish those beliefs with the least-explanatory power and supporting evidence, because they are less entrenched. The more entrenched beliefs dominate (" $\leq$ ") the lesser entrenched beliefs when $\left\{\left(\mathrm{BEL}_{1} \rightarrow \mathrm{BEL}_{2}\right) \rightarrow\left(\mathrm{BEL}_{1} \leq \mathrm{BEL}_{2}\right)\right\}$ so that $k_{2}$ comprises the "inclusion maximal" set $\left(\mathrm{BEL}_{1}, \mathrm{BEL}_{2}, \ldots \mathrm{BEL}_{\mathrm{n}}\right) \mid\left(k_{1} \nrightarrow\right.$ $\left.\mathrm{BEL}_{\mathrm{old}}\right)$ and there is minimal information loss. AGM refers to the beliefs that stay as "remainders." The remainders comprising $k_{2}$ are the maximally-large set of BEL following deletion of $\mathrm{BEL}_{\mathrm{old}}$ that do not imply any $\mathrm{BEL}_{\mathrm{old}}$, or their derivatives, remaining in $k_{1}$.

3. The exact mix of BEL $x^{\oplus}$ and BEL $x^{\ominus}$ selected by CON is determined by the preference function $\gamma(\$ 1.8 .1$, above), which specifies the minimum set of (BEL $\left.x \in k_{1}\right)$ that ought to be retained in $k_{2} . \gamma$ should select $k(x)$ in order of plausibility; $\left(k_{2} \gamma k_{1}\right)$ represents $k_{2}$ as more likely than $k_{1}$, given $\mathrm{BEL}_{\text {new. }}$. In other words, $\gamma$ should select those BEL $x$ most likely to result in a more functional (less dysfunctional) $k_{2}$. It follows that the most preferred candidates $\gamma$ should select to delete from $k_{1}$ (after steps 3.3.1 and 3.3.2) are $\mathrm{BEL}^{\ominus}$, such as automatic negative thoughts and their corollary intermediate beliefs and core beliefs, in order to maximize CON's effectiveness. The remainders then will be $\mathrm{BEL}^{\oplus}$.

4. If $\gamma$ selects a maximally-consistent set of $k_{1}$ that $\nrightarrow \mathrm{BEL}_{\mathrm{old}}$ ) to become $k_{2}$, then $\mathrm{CON}$ is a "partial meet contraction." If $k_{2}$ ends up being populated with only one BELx (unlikely), then CON is a "maxichoice contraction." If CON selects all of the BEL comprising $k_{1}$ (thus $k_{2}$ ends up being populated with all of the them), then CON is a "full meet contraction" 15 ".

We hypothesize that $\mathrm{CON}$ is the most problematic maneuver for an AGM agent, because its contribution to cognitive restructuring depends on whether it operates on a $\mathrm{BEL}^{\oplus}$ or a $\mathrm{BEL}^{\ominus}$. If the $\mathrm{BEL}$ that are being deleted are $\mathrm{BEL}^{\ominus}$, then the remainders will be $\mathrm{BEL}^{\oplus}$. This corresponds with the intuitive requirement that successful cognitive restructuring should eliminate dysfunctional $\mathrm{BEL}^{\ominus}$, while leaving $\mathrm{BEL}^{\oplus}$ alone. On the other hand, it also illustrates a way in which cognitive restructuring might backfire, for example, if one is so committed to a $\mathrm{BEL}^{\ominus}$ that a $\mathrm{BEL}^{\oplus}$ is deleted as a consequence. If the belief that is being deleted is a $\mathrm{BEL}^{\oplus}$, then the remainders all may end up being $\mathrm{BEL}^{\ominus}$, because they are well-entrenched. An example might be recovery following extinction using a classical conditioning model, which occurs when $k_{1} \subseteq\left\{\left(k_{1} \div\right.\right.$ $\left.\left.\mathrm{BEL}_{\text {new }}\right)+\mathrm{BEL}_{\text {old }}\right\}$. This means that if $k_{1}$ was EXP by $\mathrm{BEL}_{\mathrm{old}}$,

${ }^{15}$ There are several other possible operations one can perform using CON, including "transitively relational partial meet contraction." We do not cover these, here. but one somehow readopted or reincorporated $\mathrm{BEL}_{\mathrm{old}}$ into her $k_{1}$ belief set, then the effect of cognitive restructuring would be reversed. Or, the BEL set $\in k_{2}$ could be an ambiguous mixture of both $\mathrm{BEL}^{\ominus}$ and $\mathrm{BEL} \oplus$, in which case cognitive restructuring would only be partially successful. Building on our previous examples, Figure 5 illustrates an instance of successful belief revision using $\mathrm{CON}$.

\section{INTEGRATING AGM INTO A THEORY OF NON-LINEAR DYNAMICAL BELIEF REVISION}

We conceptualize belief revision using AGM as an emergent property of a complex, self-organizing system involving huge numbers of neurons broadly distributed throughout different brain regions, including the prefrontal cortex (PFC), Broca's area and Wernicke's area (Cogan et al., 2014). There now has been considerable research imaging regions of the brain activated by $\operatorname{BEL}(x)$, starting approximately with Greene et al. (2001), continuing through Harris et al. (2008) and d'Acremont et al. (2013). Other studies examine brain regions activated by semantic processing-the words in which beliefs are expressed. Huth et al. (2012) used WordNet (\$1.8.2, above) to identify 1705 object and action categories from several hours of nature movies. When they projected them to research participants undergoing fMRI, they were able to map semantic selectivity into smooth gradients covering much of the cortex. Crangle et al. (2013) presented their research participants with 48 spoken-word and visual depictions of sentences about the geography of Europe, half of which were true and half of which were false. They used WordNet and LSA (\$1.8.2, above) to extract and classify their propositional content-the $x$ in $\operatorname{BEL}(x)$. The resulting semantic processing was associated with characteristic features of EEG recordings. Costanzo et al. (2013) presented research participants undergoing fMRI with 140 line drawings or pictures of objects (visual stimuli) together with corresponding nouns spoken aloud (auditory stimuli). They found that both converged and were processed in the same regions of the brain during superordinate semantic categorization.

Semantic memory long has been recognized as a fundamental component of human cognition (McRae and Jones, 2013). It is "general knowledge about the world, including concepts, facts and beliefs" and is acquired through experience, thereby "grounding knowledge in distributed representations across brain regions that are involved in perceiving or acting" (Yee et al., 2014, p. 353). Semantic network structure plays a key role in the formulation of ideas and the ways in which they are combined and conceptually associated (Goñi et al., 2011; Marupaka et al., 2012). It accommodates both abstract concepts and concrete ones, the former associated with the medial PFC and the superior temporal sulcus, the latter associated with the bilateral intraparietal sulcus (Wilson-Mendenhall et al., 2013). It represents cognitive information either as specific autobiographical episodes or more general semantic knowledge, each with different subjective experiences (Heisz et al., 2014). Rabinovich et al. (2012b, p. 81) characterize it as a "space of interconnected information items," where "each item [is a separate] dynamical element" and "the dynamics of thinking (or consciousness) is a flow in a semantic space." 


\begin{tabular}{|c|c|c|}
\hline$\left\{k_{1}\right\} \mathrm{BEL}_{\text {old }}$ & $\Delta_{\text {bel }}$ & $\left\{k_{2}\right\} \mathrm{BEL}_{\text {new }}$ \\
\hline $\begin{array}{l}\mathrm{BEL}_{1} \ominus=\text { "My boss is going } \\
\text { to get angry." }\end{array}$ & & $\mathrm{BEL}_{1}^{\ominus}=$ deleted. \\
\hline $\begin{array}{l}\mathrm{BEL}_{2} \ominus=\text { "My colleagues } \\
\text { will disrespect me." }\end{array}$ & & $\mathrm{BEL}_{2}{ }^{\ominus}=$ deleted. \\
\hline $\begin{array}{l}\mathrm{BEL}_{3} \odot=\text { "My opinion } \\
\text { doesn't count." }\end{array}$ & & $\mathrm{BEL}_{3}{ }^{\ominus}=$ deleted. \\
\hline $\begin{array}{l}\mathrm{BEL}_{4}=\text { "The last time I } \\
\text { was late for work, my boss } \\
\text { was understanding." }\end{array}$ & & $\begin{array}{l}\mathrm{BEL}_{4}^{\oplus}=\text { "The last time I was } \\
\text { late for work, my boss was } \\
\text { understanding." }\end{array}$ \\
\hline CON & $\begin{array}{l}\mathrm{BEL}_{1}{ }^{\ominus}=\text { "My boss is going to } \\
\text { get angry." }\end{array}$ & \\
\hline CON & $\begin{array}{l}\mathrm{BEL}_{2}{ }^{\ominus}=\text { "My colleagues will } \\
\text { disrespect me." }\end{array}$ & \\
\hline CON & $\begin{array}{l}\mathrm{BEL}_{3}{ }^{\ominus}=\text { "My opinion doesn't } \\
\text { count." }\end{array}$ & \\
\hline
\end{tabular}

FIGURE 5 | CON.

This body of work supports a conclusion that $\{$ BEL $\mid$ EVID $\}$ is not a specific topological location or ontogenetic landscape within the brain. Rather, it is a type of neural activity or pattern of activation that occurs within a comprehensive neural system. When one believes something, one enters into a series of hybrid doxastic/semantic states, which can be functionally represented as a non-linear, dynamical process-a belief revision network occurring in a global workspace-such as that depicted at Figure 6 (while Figure 6 depicts a two-dimensional surface, it should be understood as a multi-dimensional space; Figure 7 depicts an alternative perspective).

It also requires a reconceptualization of the relationship between beliefs and semantics. Unlike an fMRI or EEG recording depicting brain activity, a belief set cannot be described as a geometrical object or in statistical terms. Rather, it is an encoded set of semantic propositions, embodying emergent semantic properties in its very organization (Juarrero, 1999). A belief set creates an internal symbolic mental representation based on one's assessment of its conditions of satisfaction ( $\$ 1.5$, above); one can imagine the conditions of satisfaction being enacted or realized $^{16}$. It interacts with other brain regions responsible for

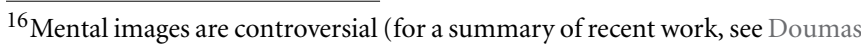
and Hummel, 2012; Markman, 2012; Reisberg, 2014; and Shea, 2013). We are not committed to a theory that one creates actual, static mental representations in the brain. They are not pictures, rather, "depictive representations interpreted by cognitive processes at play in other systems" (Borst, 2014, p. 84). They have "several levels of complexity, from sparse, atomic concepts to complex, knowledge intensive ones" (Rips et al., 2012, p. 177). An agent's
}

perception, cognition, emotion, language and behavior. They are embedded within a manifold or phase plane together with physiological assets such as blood flow and oxygen. The phase plane is in a constant state of flux, flexibly changing in response to environmental constraints and internal demands (Kelso, 1999). Belief revision is a dynamic pattern of activity occurring within the phase plane.

Some beliefs initially are stored in long-term memory. These most likely are enduring, persistent beliefs about self, others, world and future; background or network beliefs of the sort described at $\$ 1.9$, above; and core beliefs of the sort described at $\$ 2.3 .3$, above. They are recalled into short-term memory in response to decision points, environmental affordances and outcomes, and other multiple attractors. The network's attractors constitute a "self-organized space with emergent properties that can only be characterized as semantic" because they "embody [word] meaning[s] or sense[s] in the organization

behavior must be flexible in order to respond to her circumstances, and mental representations play an important role in enabling her to do so (Egan, 2012, p. 250). Perception, for example, may be more of a process whereby a perceiver skillfully interacts with her environment. The real world presents way too much information for the perceiver to encapsulate it in an isomorphic mental image. Rather it is like a gigantic external memory, supplying a series of cues, which the perceiver can access as necessary (Noë, 2004). We do not, of course, contend that one literally perceives the words comprising the semantic formulation of one's belief set (in a manner similar to the way the Arnold Schwarzenegger character in the movie Terminator III movie was able to scroll through different belief-action options before selecting a particular alternative). 


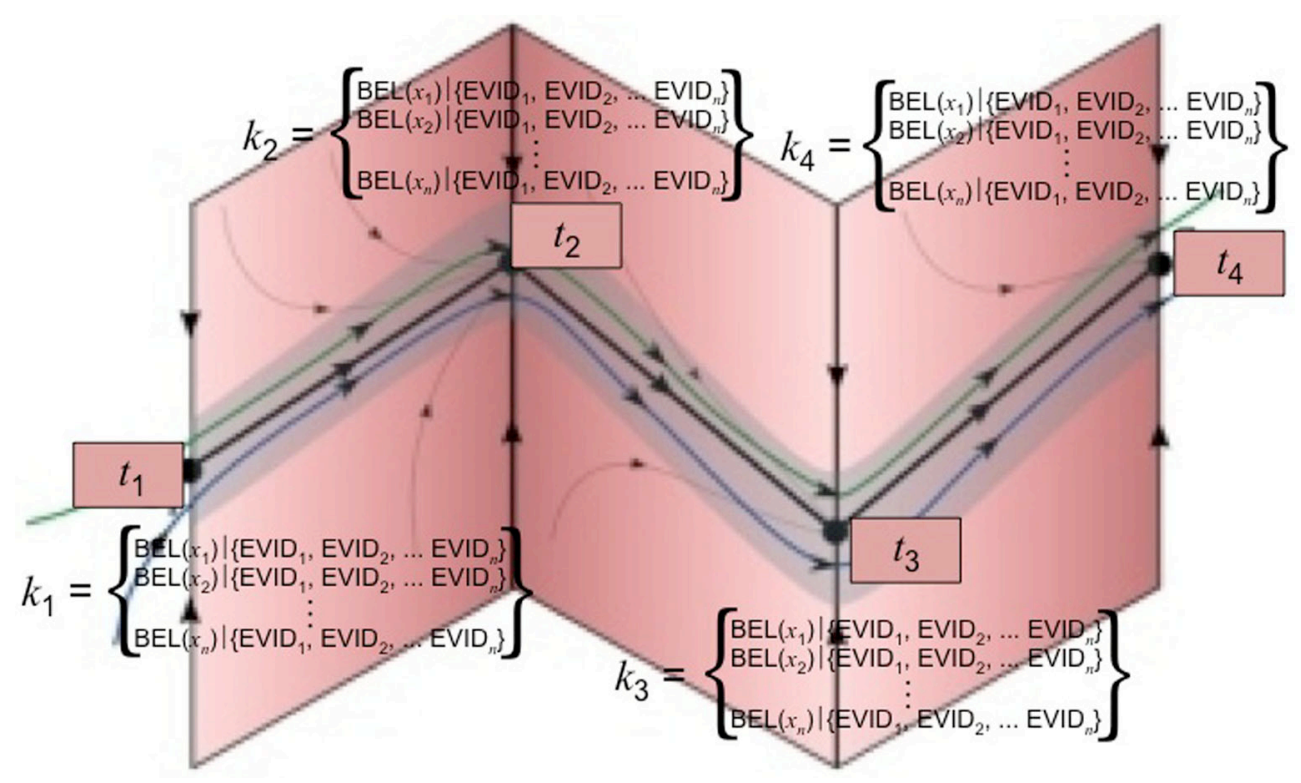

FIGURE 6 | Hypothesized pathways for belief revision-conceptualization 1. Adapted from (Rabinovich et al., 2010a). Used with permission.

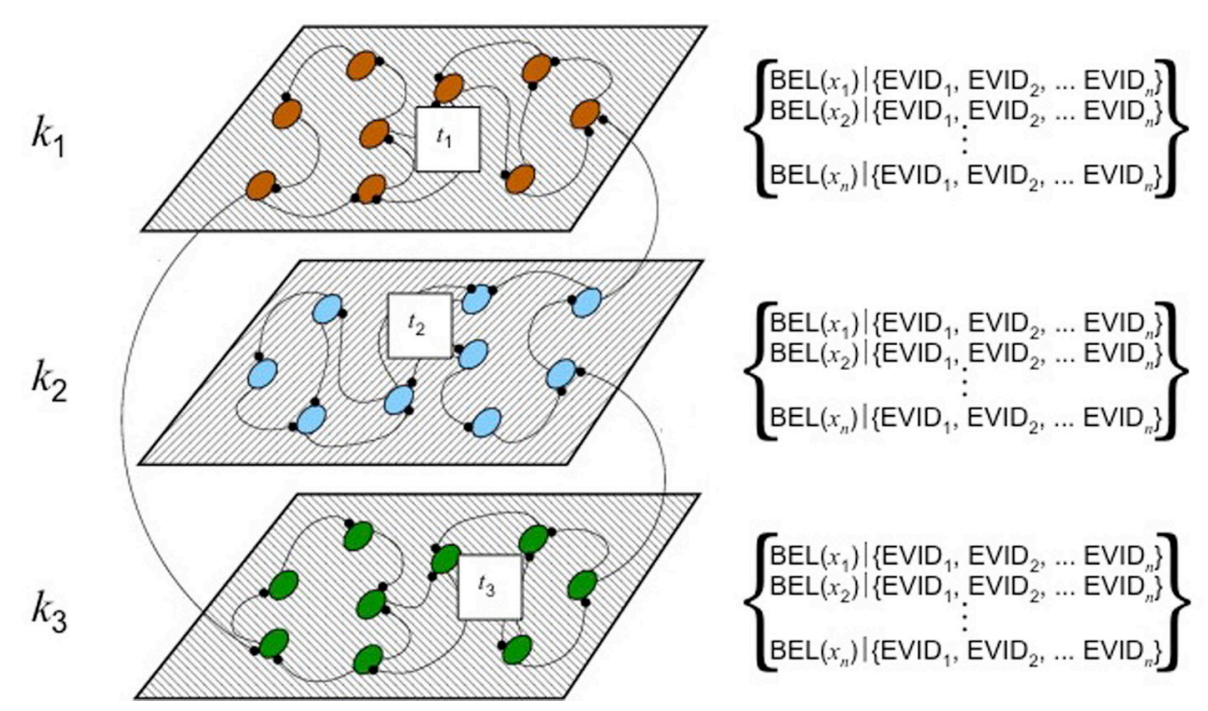

FIGURE 7 | Hypothesized pathways for belief revision-conceptualization 2. Adapted from (Rabinovich et al., 2010b). Used with permission.

of the relationships that constitute the higher-dimensional space" (Juarrero, 1999, p. 167). Initially, the phase plane represents all possible states of the belief-generating and belief-revision systems. It has a large number of degrees of freedom. It is unstable in that small changes to initial conditions-both perceived and imaginal-have the potential to become radically amplified, resulting in any number of different multi-stable belief sets. While the output belief set at $k_{n}$ depends to some extent on the input belief set at $k_{1}, k_{n}$ is asymmetrical and cannot be reliably predicted by $k_{1}$. Arguably, it exhibits chaotic dynamics because it would be difficult to specify the individual beliefs comprising the belief set as it evolves into novel and surprising states that are unexpectedly both deterministic and stochastic (non-deterministic) (Nicolis and Prigogine, 1989).

The belief revision system is transient. At $t_{1}$, all possible belief trajectories (starting with the system's initial conditions) intersect the phase plane in a structure similar to a Poincaré surface. As it evolves forward in time, it is bombarded with evidence-information derived from its interactions with the environment and subsequent interpretations. It becomes destabilized and undergoes non-equilibrium, dissipative phase transition. Individual beliefs transverse each attractor's basin of attraction and converge into specific belief sets, which consolidate at saddle equilibrium points $\left\{t_{1}, t_{2} \ldots t_{n}\right\}$. They can be conceptualized 
as a form of Mandelbrot fractal. Broader attractor basins capture or entrain a wider range of beliefs, depending on their strength. Because of the system's chaotic dynamics and each point's turbulent behavior, they resemble strange attractors. Convergence results in heteroclinic binding (Rabinovich et al., 2010b) of different evidentiary data to individual beliefs, which recruit resources and attempt to gain priority using the preference function $\gamma$ as described at $\$ 1.8 .1$, above. The system bifurcates as new beliefs are formulated based on $\{$ BEL $\mid$ EVID ( $\$ 1.1$, above), revised conditions of satisfaction ( $\$ 1.5$, above), new evidence/information received as a result of interactions with the environment ( $\$ 2.2$, above), and associated evaluative processes.

Belief revision occurs as belief sets sequentially progress or are deflected from one metastable state to another, forming a heteroclinic channel. The separatices are ridges defining its boundaries. They constrain the flow of resources available to each belief set by modifying the phase plane or the possible trajectories of movements within it. As one belief set begins to dominate, it acquires and sustain coherence, crowding out the semantic space potentially accessible to other beliefs. At some point it reaches critical mass and overcomes an inertial threshold, compelling its migration from $t_{1}$ to $t_{n}$. During this process, the $k_{1}$ belief set competes with the $k_{2}$ belief set (then $k_{2}$ with $k_{3}$, etc.) to alter its composition using CON, EXP, or REV, either in response to cognitive restructuring or exposure/response prevention with associated environmental feedback, followed by belief revision.

Since the individual beliefs comprising each belief set displace each other (using CON, EXP, or REV), this is a zero-sum, inhibitory process. The sequence of equilibrium points in the heteroclinic channel form a heteroclinic belief revision network. This process typically remains non-conscious until at $t_{n}$, when elements of the belief set acquire salience or otherwise are extracted using typical CBT clinical techniques and protocols ${ }^{17}$. The combination of non-linearity and non-equilibrium, context-sensitive constraints initially permits multiple solutions, which have the potential to emerge from and be expressed within a diversified assortment of behaviors (Nicolis and Prigogine, 1989). Numerous beliefs compete in a kind of winnerless competition (Rabinovich et al., 2010a). As it stabilizes, though, the belief revision network appropriates a single behavioral output channel. The behavior semantically satisfies the intentions motivating it (the conditions of satisfaction of the associated belief sets, $\$ 1.5$, above). Upon its conclusion at $t_{n}$, the reformulated beliefs comprising the $k_{n}$ belief set are inserted (or reinserted) back into long-term memory. The behavioral stream transfers to an adjacent nonlinear dynamical system for action. Since emotion regulation also plays

\footnotetext{
${ }^{17}$ In this we are in accord with Dehaene (2014, p. 8) and Searle (1992, p. 152) to the effect that "The notion of an unconscious mental state implies accessibility to consciousness. We have no notion of the unconscious except as that which is potentially conscious." Metaphorically, beliefs are like objects within a multi-dimensional hologram; at any given time we are able to observe only a small portion of them within a potentially vast space-time continuum. Our characterization of the belief-generation and belief-modification process does not implicate any particular theory of action or agency, other than the basic principle that behavior is the action-expression of belief.
}

an important role in belief revision (Boden and Gross, 2013), associated emotions also are reregulated $(\$ 2.1 .4 \text {, above })^{18}$.

Cognition and behavior comprise a single autocatalytic unit and it is difficult to assess their respective influences at any $t_{n}$. Neurocognitive methods do not yet have sufficient precision to discriminate between the two (Morrison and Knowlton, 2012). There are no studies persuasively isolating the cognitive component from the behavioral one. Both require selective deployment of attentional, cognitive and affective resources. Unless belief revision was assessed immediately following cognitive intervention, before enactment of any behavior, it would not be possible to isolate the floor effect of cognitive change and control for reinforcement effects, because cognitive change already would be in the process being incrementally reinforced (for an early and unpersuasive attempt to do so based on the concept of "self-focused attention," see Wells, 2006). Any kind of change arguably results in a form of behavior. A recent study on the efficacy of mindfulness-based cognitive therapy (Kuyken et al., 2010)-seemingly, the paradigm case of a cognitive interventioncorrectly noted that "these interactive mediation effects indicate that treatment changes the nature of the relationship between cognitive reactivity and outcome" (p. 1110).

What we can say is that together, they comprise a heterogeneous, self-organized, complex adaptive system (Juarrero, 1999) (in this sense, realizing Beck's concept of cognition as an information processing system, $\$ 2.3 .3$, above). Both are temporally and contextually embedded, exchanging information and energy with each other depending on the task at hand, the level of one's skills or expertise to accomplish it, and feedback from the environment. Structure and patterns emerge from repeated cycling involving the cooperation of many individual parts (Thelen and Smith, 2000). Although the system initially is out of equilibrium, with high entropy, it self-organizes by assuming a structure allowing it to operate more efficiently (Guastello and Liebovitch, 2009). Repeated behavioral stimulation and learning history facilitate signal transmission between neurons. Neural plasticity promotes Hebbian-type long-term potentiation, which in turn cascades into further hybrid cognitive-behavioral activation and reinforcement, strengthening attractors and facilitating the development of more predictable belief trajectories within the semantic phase plane. "Through repeated activation of a pattern the connections between units that are activated simultaneously become stronger and the whole pattern becomes an attractor." Thus, even if only partially activated, "the network can complete the pattern by a process of iterative spreading activation" so "the previously learned pattern is recovered in a number of updating cycles in which the activation level of each unit is adjusted according to the activation levels of the other units and the strength of the connections between the units" (Pecher, 2013, p. 359). As a result, conditions of satisfaction $(\$ 1.5$, above) are revised, together with their corresponding internal symbolic mental representations ( $\$ 1.1$, above). These brain-environmental interactions comprise a negative feedback

\footnotetext{
${ }^{18}$ Though we disagree with Boden and Gross' naive model of how this works (pp. 591-2), which appears to be the result of reading too much literature on acceptance and commitment therapy (ACT).
} 
loop if they increase the incidence of target behavior; a positive one, if it decreases.

From a clinical standpoint, many cognitive interventions (such as mindfulness) are inherently mental and remain thoroughly solipsistic even as they reinforce and are reinforced by new behavior. Many principles of acceptance and commitment therapy (ACT) are cognitively front-loaded, for example, using metaphor as a means of identifying and developing a valued direction and defusing from one's private mental experiences (Hayes et al., 2012). Other examples are motivational interviewing for substance abuse (Miller and Rollnick, 2012); cognitive behavioral analysis system of psychotherapy (CBASP) for depression (McCullough, 2000); and cognitive processing therapy for PTSD (Resick et al., 2002). Behavioral factors, on the other hand, more clearly dominate interventions such as behavioral activation for depression; exposure/response prevention treatment for obsessive-compulsive disorder or attention deficit disorder; and prolonged exposure therapy for PTSD (Foa et al., 2007). With its dual emphases on learning (cognitive) then applying (behavioral) skills, DBT for borderline personality disorder (\$2.1.4, above; Linehan, 1993) lies somewhere in the middle.

In some instances behavioral therapy is a more plausible intervention than cognitive therapy, and vice versa. Unquestionably it is possible to train up organisms with little cognitive processing capacity to demonstrate learned behavior. A 700-kg alligator, for example, has a brain that would fit comfortably inside of a teaspoon (Coulson and Herbert, 1981), yet still is capable of learning in the sense of (Squire and Kandel, 1998) ${ }^{19}$. In principle, it would be amenable to behavioral therapy. At some point, though, higher-order propositions must be expressed using natural language or a natural language equivalent ${ }^{20}$. Without it, propositions would neither be true nor false; the concept of truth builds upon veridical experience. Nor would beliefs have conditions of satisfaction ( $\$ 1.5$, above), nor would psychopathological beliefs have none ( $\$ 1.6$, above). Unlike behavior therapy, cognitive therapy depends on semantics. For this reason, as per $\$ 2.1 .3$, above, it is unclear whether persons with thought disorders can benefit from it (compare Grant et al., 2012 with Aggarwal and Basu, 2013; for a current overview, see Bachman and Cannon, 2012; and Jauhar et al., 2014). While of course outcomes lie on a continuum, arguably, it would be ineffective in principle for those toward the far end of the spectrum. If a person remains impervious to environmental feedback-she is unable to develop adaptive cognitions and activate belief revision-we are inclined to say that something is impeding the assimilation of new evidence, or that her information processing systems require recalibration. Functionally, she may be in a concrete operational stage, or otherwise incapable of abstract thought or metacognition. Having

\footnotetext{
${ }^{19}$ This is the double entendre behind the title of B.F. Skinner's famous paper "Superstition in the Pigeon" (1947). Superstition is a form of cognition, whereas pigeons only are capable of learned behavior.

${ }^{20}$ There is no bright-line test for this, either. The meaning of simple propositions can be enacted using language-like behavior, such as Quine's famous example of a speaker using ostension to point to a rabbit, while uttering the word "gavagi" to designate a rabbit-like stage or rabbit-like behavior (Quine, 1964).
}

a theory of mind-being able to think about thoughts-may be a necessary component of psychological change (Saxe and Young, 2014). One solution from an operant conditioning perspective might be to increase positive reinforcement $\left(\mathrm{R}^{\oplus}\right)$ or to titrate down punishment using negative reinforcement $\left(\mathrm{R}^{\ominus}\right)$ in order to upregulate the desired behavior, with a view toward mobilizing additional cognitive resources.

Most likely cognition and behavior shuttle back and forth quickly depending on the client's perceptions, emotions, language capability, attentional focus, the context in which behavior occurs, the nature of the transaction the client is having with her/his environment, experience/learning history, genetics, neurochemistry, interoceptive sensitivity, memory capacity, heuristics, intuition, vulnerabilities, intentions, skills, values, and a variety of other factors. Their different trajectories oscillate (Schultz and Heimberg, 2008) in what Rabinovich et al. (2010b) would characterize as a heteroclinic channel between metastable states. Because the brain is a complex system with a variety of different inputs and outputs, neither cognition nor behavior can be controlled in isolation (Ruths and Ruths, 2014). From a clinical standpoint, target behavior should progressively and dynamically reduce. As depicted at Figures 8, 9, their relationship is transactional. The exact mix of each depends not only on the type of therapy but also stages in the therapeutic process. For example, the manic phase of bipolar disorder (DSM-5 $\$ 296 . x x)$ might be more amenable to cognitive therapy, whereas the depressive phase might be more amenable to behavioral therapy (Leahy, 2005). Daugherty et al. (2009) characterized this as a Liénard oscillator with autonomous forcing. From the standpoint

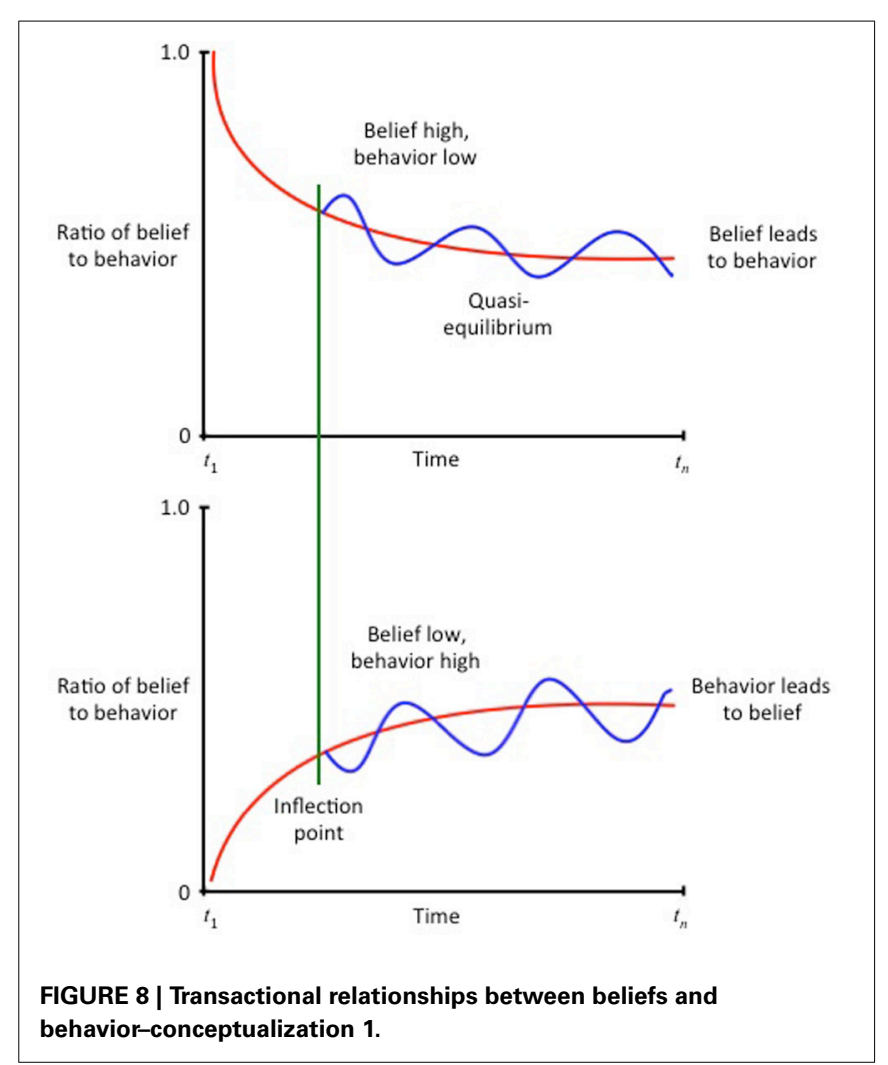




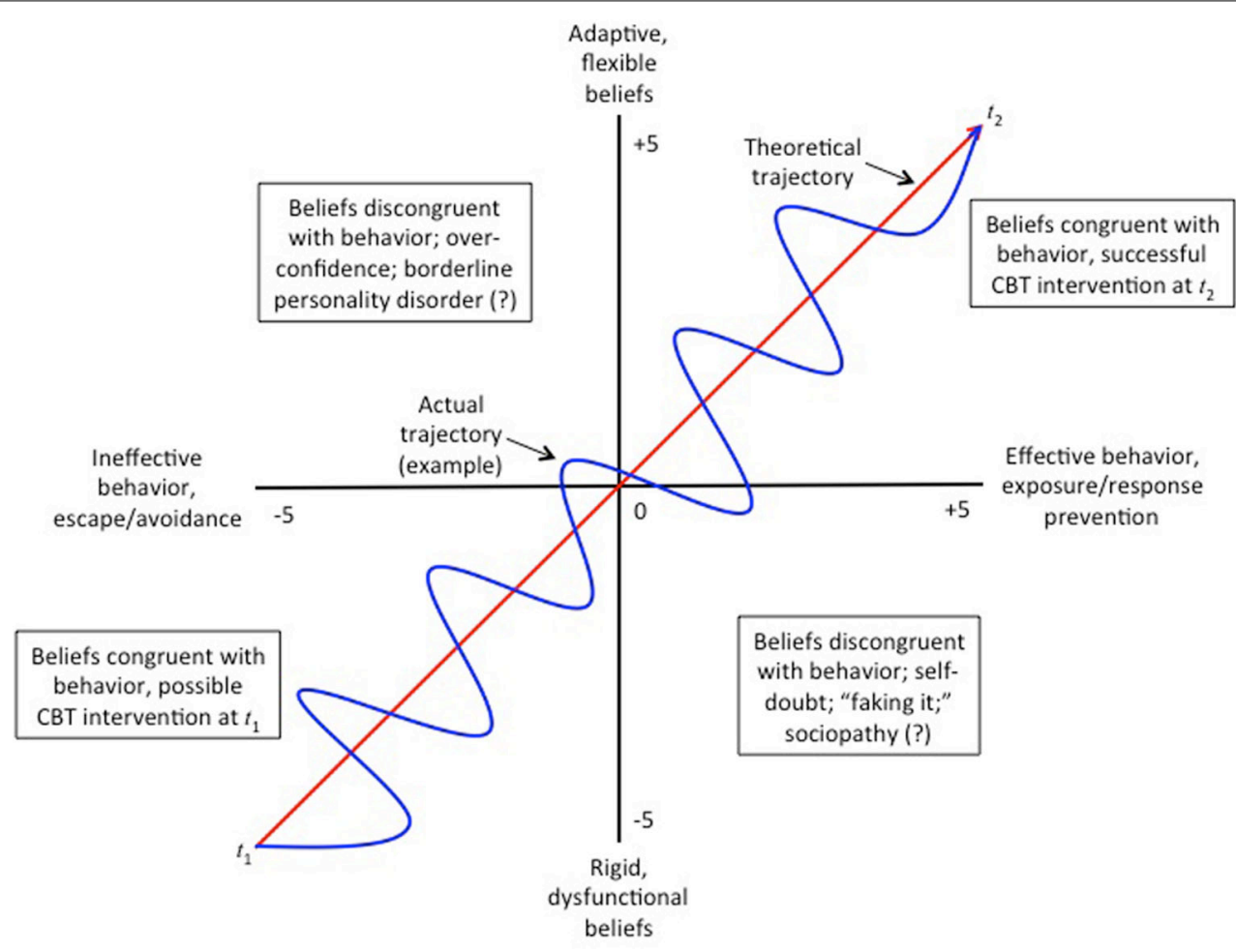

FIGURE 9 | Transactional relationships between beliefs and behavior-conceptualization 2.

of belief revision semantics, the theme of the substantive propositional content (" $x$ ") remains the same, even as the propositional attitude toward it changes, e.g., if the domain is "affection," then manic $=$ "adorable" whereas depressed = "unlovable." Conceptually, behavioral reformulation and cognitive reconstruction serially propel it in a dynamic progression from $t_{1}$ through $t_{n}$ as different inhibitory and stimulating paradigms take effect. At some point in this process-an extremely interesting one from the standpoint of cognitive science-their trajectories intersect and one transitions into the other. Both are active ingredients of therapeutic change.

\section{CONCLUSION}

The ultimate goal of cognitive restructuring or belief consolidation following exposure/response prevention should be thorough overhaul of a meaningful subset of one's entire belief system. Simply inducing doubt is not sufficient. An example of such a paradigm shift might be a prisoner on death row who is exonerated by new DNA evidence, resulting in radical reformation of her knowledge base, or Dostoyevsky's experience in front of a mock firing squad (Bloom, 2005). This is every bit as profound and disruptive as the transition from Ptolemaic astronomy to Copernican astronomy, or from Newtonian physics to Einstein physics, or through the socalled three waves of cognitive behavioral therapy (Hayes, 2004). Thomas Kuhn (1962/2012) labeled these "scientific revolutions"on an individual level, they might be labeled "personal revolutions."
In addition to making a case for AGM, one of our main objectives in this review has been to illustrate a point of intersection between cognitive science and clinical psychology, two fields which long have enjoyed an uneasy rapprochement (Macleod, 2010). "The study of psychopathology has. . become an important facet of the cognitive sciences, and the cognitive sciences have, in turn, exerted an important influence on many regions of psychiatry" (Cratsley and Samuels, 2013, p. 413). One of the characteristics of many cognitive science theories is that while each step of the argument makes sense, when viewed as a complete chain of inferential reasoning, the transition from premises to conclusion may be implausible, in a C.P. Snow (1959/2012)type sense. Like a salmon swimming upstream, one ends up in a very small pond. Clinical psychology, in turn, depends operationally on protocols that first were devised over a quarter of a century ago. The prospects for détente are not as far-fetched as they initially might seem. For example, on April 1, 2014, the Max Planck Society announced a $€ 5$ million investment in a new center for computational psychiatry to be based in London and Berlin, with a view toward uncovering relationships between cognition and psychopathology of the sort we hypothesize (Siddique, 2014).

We submit that the best way to think of our initiative is that it is an exercise in translational research. It applies a form of nonlinear analysis to the study of complex systems in cognitive science and behavioral analysis. Even though it may not exactly mirror actual, common sense psychological activity, logical reasoning should "clarify, sharpen, systematize the purely semantic-level 
characterization of the demands on any such implementation, biological or not" (Dennett, 1984/2006, p. 449); to "provide an account of our cognitive architecture-which specifies the basic operations, component parts, and organization of the mind" (Samuels, 2012). It also demonstrates how recent work in experimental cognitive science can be combined with clinical psychology to inform the process of psychological change.

\section{REFERENCES}

Abbott, A. (2013). Solving the brain. Nature 499, 272-274. doi: 10.1038/499272a

Afraimovich, V., Young, T., Muezzinoglu, M. K., and Rabinovich, M. I. (2011). Nonlinear dynamics of emotion-cognition interaction: when emotion does not destroy cognition? Bull. Math. Biol. 73, 266-284. doi: 10.1007/s11538-0109572-x

Aggarwal, M., and Basu, D. (2013). Cognitive therapy in patients with schizophrenia. JAMA Psychiat. 70, 543-544. doi: 10.1001/jamapsychiatry.2013.284

Albergotti, R. (2014). Zuckerberg, musk invest in artificial intelligence company. Wall Street J. Available online at: http://blogs.wsj.com/digits/2014/03/ 21/zuckerberg-musk-invest-in-artificial-intelligence-company-vicarious/

Alchourrón, C. E., Gärdenfors, P., and Makinson, D. (1985). On the logic of theory change: partial meet contraction and revision functions. J. Symbolic Logic 50, 510-530. doi: 10.2307/2274239

American Psychiatric Association. (2013). Diagnostic and Statistical Manual of Mental Disorders, 5th Edn. Washington, DC: Author.

Arlo-Costa, H. (2007). The logic of conditionals. Stanford Encyclopedia Philos. Available online at: http://plato.stanford.edu/entries/logic-conditionals/

Arntz, A. (2002). Cognitive therapy versus interoceptive exposure as treatment of panic disorder without agoraphobia. Behav. Res. Ther. 40, 325-341. doi: 10.1016/S0005-7967(01)00014-6

Austin, J. L. (1956/1970). A plea for excuses. Proc. Aristotelian Soc. 57, 1-30. Reprinted in (1970). J. L. Austin-Philosophical Papers (175-204), eds J. O. Urmson and G. J. Warnock Oxford: Oxford University Press.

Austin, J. L. (1962). How to Do Things with Words. New York, NY: Oxford University Press.

Bachman, P., and Cannon, T. (2012). "The cognitive neuroscience of thought disorder in schizophrenia," in The Oxford Handbook of Thinking and Reasoning, eds K. J. Holyoak and R. G. Morrison (New York, NY: Oxford University Press), 673-700.

Bahr, S. S., Brown, G. K., and Beck, A. T. (2008). Dysfunctional beliefs and psychopathology in borderline personality disorder. J. Pers. Disord. 22, 165-177. doi: 10.1521 /pedi.2008. 22.2.165

Beck, J. S. (2011). Cognitive Behavior Therapy-Basics and Beyond, 2nd Edn. New York, NY: Guilford Press.

Bernstein, A., Stickle, T. R., and Schmidt, N. B. (2013). Factor mixture model of anxiety sensitivity and anxiety psychopathology vulnerability. J. Affect. Disord. 149, 406-417. doi: 10.1016/j.jad.2012.11.024

Bernstein, A., Stickle, T. R., Zvolensky, M. J., Taylor, S., Abramowitz, J., and Stewart, S. (2010). Dimensional, categorical, or dimensional-categories: testing the latent structure of anxiety sensitivity among adults using factor-mixture modeling. Behav. Ther. 41, 515-529. doi: 10.1016/j.beth.2010.02.003

Bickle, J., Mandik, P., and Landreth, A. (2010). The philosophy of neuroscience. Stanford Encyclopedia Philos. Available online at: http://plato. stanford.edu/entries/neuroscience/

Bilder, R. M., Sabb, F. W., Cannon, T. D., London, E. D., Jentsch, J. D., Parker, D. S., et al. (2009a). Phenomics: the systematic study of phenotypes on a genome-wide scale. Neuroscience 164, 30-42. doi: 10.1016/j.neuroscience.2009.01.027

Bilder, R. M., Sabb, F. W., Parker, D. S., Kalar, D., Chu, W. W., Fox, J., et al. (2009b). Cognitive ontologies for neuropsychiatric phenomics research. Cogn. Neuropsychiatry 14, 419-450. doi: 10.1080/13546800902787180

Bloom, H. (2005). Fyodor Dostoevsky. Langhorne, PA: Chelsea House Publishers.

Boden, M. T., and Gross, J. J. (2013). "An emotion regulation perspective on belief change," in The Oxford Handbook of Cognitive Psychology, ed D. Reisberg (Oxford: Oxford University Press), 585-599.

Boden, M. T., John, O. P., Goldin, P. R., Werner, K., Heimberg, R. G., and Gross, J. J. (2012). The role of maladaptive beliefs in cognitive-behavioral therapy: evidence from social anxiety disorder. Behav. Res. Ther. 50, 287-291. doi: 10.1016/j.brat.2012.02.007
Borst, G. (2014). "Neural underpinning of object mental imagery, spatial imagery, and motor imagery," in The Oxford Handbook of Cognitive Neuroscience, vol. 1 eds K. N. Ochsner and S. M. Kosslyn (New York, NY: Oxford University Press), 74-87.

Braun, D. (2007). Indexicals. Stanford Encyclopedia Philos. Available online at: http://plato.stanford.edu/entries/indexicals/

Brisard, F. (2011). "H.P. Grice," in Philosophical Perspectives for Pragmatics, eds M. Sbisà, J.-O. Östman, and J. Verschueren (Philadelphia, PA: John Benjamins Publishing Co.), 104-124 doi: 10.1075/hoph.10.10bri

Bryant, R. A., Moulds, M. L., Guthrie, R. M., Dang, S. T., and Nixon, R. D. (2003). Imaginal exposure alone and imaginal exposure with cognitive restructuring in treatment of posttraumatic stress disorder. J. Consult. Clin. Psychol. 71, 706-712. doi: 10.1037/0022-006X.71.4.706

Buckner, R. L., Andrews-Hanna, J. R., and Schacter, D. L. (2008). The brain's default network: anatomy, function, and relevance to disease. Ann. N.Y. Acad. Sci. 1124, 1-38. doi: 10.1196/annals.1440.011

Butler, A. C., Chapman, J. E., Forman, E. M., and Beck, A. T. (2006). The empirical status of cognitive-behavioral therapy: a review of meta-analyses. Clin. Psychol. Rev. 26, 17-31. doi: 10.1016/j.cpr.2005.07.003

Bystritsky, A., Khalsa, S. S., Cameron, M. E., and Schiffman, J. (2013). Current diagnosis and treatment of anxiety disorders. P T. 38, 30-57.

Bystritsky, A., Nierenberg, A. A., Feusner, J. D., and Rabinovich, M. (2012). Computational non-linear dynamical psychiatry: a new methodological paradigm for diagnosis and course of illness. J. Psychiatr. Res. 46, 428-435. doi: 10.1016/j.psychires.2011.10.013

Carey, B. (2012). Paul Allen gives millions for brain research. N.Y. Times. Available online at: http://www.nytimes.com/2012/03/22/health/research/ paul-allen-adding-300-million-for-brain-research.html

Carnap, R. (1947/1988). Meaning and Necessity. Chicago, IL: University of Chicago Press.

Carnota, R., and Rodríguez, R. (2011). "AGM Theory and artificial intelligence," in Belief Revision Meets Philosophy of Science, Logic, Epistemology, and the Unity of Science, eds E. Olsson and S. Enqvist (Dordrecht, NL: Springer Science+Business Media), 1-42. doi: 10.1007/978-90-481-9609-8_1

Carruthers, P. (2012). "Language in cognition," in The Oxford Handbook of Cognitive Science, eds E. Margolis, R. Samuels, and S.P. Stich (New York, NY: Oxford University Press), 382-401. doi: 10.1093/oxfordhb/9780195309799. 003.0016

Carter, M. M., Forys, K. L., and Oswald, J. C. (2008). “The cognitive-behavioral model," in Handbook of Clinical Psychology-Vol. 1-Adults, eds A. Gross and M. Hersen (Hoboken, NJ: Wiley), 171-204.

Chomsky, N. (1955). Logical syntax and semantics: their linguistic relevance. Language 31, 36-45. doi: 10.2307/410891

Chomsky, N. (1959). Review of verbal behavior, by B. F. Skinner. Language 35, 26-58.

Chomsky, N. (1965). Aspects of the Theory of Syntax. Cambridge, MA: MIT University Press.

Chomsky, N. (1977). Essays on Form and Interpretation. New York, NY: NorthHolland.

Churchland, P. M., and Churchland, P. S. (1998). On the Contrary: Critical Essays 1987-1997. Cambridge, MA: MIT Press.

Churchland, P. M., and Churchland, P. S. (2013). "What are beliefs?" in The Neural Basis of Human Belief Systems, eds F. Krueger and J. Grafman (New York, NY: Psychology Press), 1-18.

Cogan, G. B., Thesen, T., Carlson, C., Doyle, W., Devinsky, O., and Pesaran, B. (2014). Sensory-motor transformations for speech occur bilaterally. Nature 507, 94-98. doi: 10.1038/nature12935

Corazza, E. (2011). "Indexicals and demonstratives," in Philosophical Perspectives for Pragmatics, eds M. Sbisà, J.-O. Östman, and J. Verschueren (Philadelphia, PA: John Benjamins Publishing Co), 131-152. doi: 10.1075/hoph.10.12cor

Costa, H. A., and Pedersen, A. P. (2011). "Belief revision," in The Continuum Companion to Philosophical Logic, eds R. Pettigrew and L. Horsten (New York, NY: Continuum International Publishing Group), 450-502.

Costanzo, M. E., McArdle, J. J., Swett, B., Nechaev, V., Kemeny, S., Xu, J., et al. (2013). Spatial and temporal features of superordinate semantic processing studied with fMRI and EEG. Front. Hum. Neurosci. 7:293. doi: 10.3389/fnhum.2013.00293

Coulson, R. A., and Herbert, J. D. (1981). Relationship between metabolic rate and various physiological and biochemical parameters: a comparison of alligator, 
man and shrew. Comp. Biochem. Physiol. 69A, 1-13. doi: 10.1016/03009629(81)90632-0

Crangle, C. E., Perreau-Guimaraes, M., and Suppes, P. (2013). Structural similarities between brain and linguistic data provide evidence of semantic relations in the brain. PLoS ONE. 8:e65366. doi: 10.1371/journal.pone.0065366

Craske, M. G., Liao, B., Brown, L., and Vervliet, B. (2012). Role of inhibition in exposure therapy. J. Exp. Psychopathol. 3, 322-345. doi: 10.5127/jep.026511

Cratsley, K., and Samuels, R. (2013). "Cognitive science and explanations of psychopathology," in The Oxford Handbook of Philosophy and Psychiatry, eds K. W. M. Fulford, M. Davies, R. G. T. Gipps, G. Graham, J. Z. Sadler, G. Stanghellini and T. Thornton (Oxford: Oxford University Press), 413-433. doi: 10.1093/oxfordhb/9780199579563.013.0027

Culbertson, J., and Adger, D. (2014). Language learners privilege structured meaning over surface frequency. PNAS 10, 2014. doi: 10.1073/pnas.1320525111

Curley, S. P. (2007). The application of Dempster-Shafer theory demonstrated with justification provided by legal evidence. Judgm. Decis. Mak. 2, 257-276.

d'Acremont, M., Schultz, W., and Bossaerts, P. (2013). The human brain encodes event frequencies while forming subjective beliefs. J. Neurosci. 33, 10887-10897. doi: 10.1523/jneurosci.5829-12.2013

Dagan, I., Dolan, B., Magnini, B., and Roth, D. (2009). Recognizing textual entailment: Rational, evaluation and approaches. Nat. Lang. Eng. 15, i-xvii. doi: $10.1017 /$ S1351324909990209

Damasio, A. (1999). The Feeling of What Happens. New York, NY: Harcourt, Inc.

Dattilio, F. M., Edwards, D. J. A., and Fishman, D. B. (2010). Case studies within a mixed methods paradigm: toward a resolution of the alienation between researcher and practitioner in psychotherapy research. Psychotherapy (Chic). 47, 427-441. doi: 10.1037/a0021181

Daugherty, D., Roque-Urrea, T., Urrea-Roque, J., Troyer, J., Wirkus, S., and Porter, M. A. (2009). Mathematical models of bipolar disorder. Commun. Nonlinear Sci. 14, 2897-2908. doi: 10.1016/j.cnsns.2008.10.027

Davidson, D. (1970). "Mental events," in Experience and Theory, eds L. Foster, and J. W. Swanson (Amherst, MA: University of Massachusetts Press), 79-101. Reprinted in (2001). Essays on Actions and Events, 2nd Edn. (Oxford: Oxford University Press), 207-244. Reprinted in N. J. Block (ed.). (1980). Readings in Philosophy of Psychology, Vol. 1, (Cambridge, MA: Harvard University Press), 107-119. Reprinted in (1991). The Nature of Mind, ed D. M. Rosenthal (Oxford: Oxford University Press), 247-256. Reprinted in (1992). The Philosophy of Mind: Classical Problems/Contemporary Issues, eds B. Beakley and P. Ludlow (Cambridge, MA: MIT Press), 137-150. Reprinted in (1999). Mind and Cognition: An Anthology, 2nd Edn, ed W.G. Lycan (Malden, MA: Blackwell), 35-46. Reprinted in (2002). Philosophy of Mind-Classical and Contemporary Readings, eds D. J. Chalmers (New York, NY: Oxford University Press), 116-125. doi: 10.1093/0199246270.001.0001

Davidson, D. (1974). "Psychology as philosophy," in Philosophy of Psychology, ed S. Brown (London: Macmillan Press), 41-52. Reprinted in (2001). Essays on Actions and Events, 2nd Edn, (Oxford: Oxford University Press), 229-245. Reprinted in (1976). The Philosophy of Mind, ed J. Glover (Oxford: Oxford University Press), 101-110. Reprinted in (2006). Philosophy of Psychology, ed J. L. Bermúdez (New York, NY: Routledge), 22-30. doi: 10.1093/0199246270.001.0001

Davidson, D. (1975). “Thought and talk," in Inquires into Truth and Interpretation, eds D. Davidson (Oxford: Oxford University Press), 155-170.

Davidson, D. (1994/2005). "The social aspect of language," in Truth, Language and History, ed M. Cavell (Oxford: Oxford University Press), 109-126.

Davies, M., and Coltheart, M. (2000). "Belief revision: biases and deficits," in Pathologies of Belief, eds M. Coltheart and M. Davies (Malden, MA: Blackwell Publishers, Inc), 22-27.

Davies, M., and Egan, A. (2013). "Delusion: cognitive approaches-Bayesian inference and compartmentalization," in The Oxford Handbook of Philosophy and Psychiatry, eds K. W. M. Fulford, M. Davies, R. G. T. Gipps, G. Graham, J. Z. Sadler, G. Stanghellini, and T. Thornton (Oxford: Oxford University Press), 688-727. doi: 10.1093/oxfordhb/9780199579563.013.0042

Dehaene, S. (2014). Consciousness and the Brain-Deciphering How the Brain Codes Our Thoughts. New York, NY: Viking.

Dennett, D. C. (1984/2006). "Cognitive wheels: the frame problem of AI," in. Minds, Machines and Evolution: Philosophical Studies, ed C. Hookway (Cambridge: Cambridge University Press), 128-151. Reprinted (1987). The Robot's Dilemma: The Frame Problem in Artificial Intelligence, ed Z. W. Pylyshyn (New York, NY: Ablex Publishing), 41-64). Reprinted in (2006). Philosophy of Psychology: Contemporary Readings, ed J. L. Bermúdez (New York, NY: Routledge), 433-454. Reprinted in (1998). Brainchildren: Essays on Designing Minds, D. C. Dennett, (Cambridge, MA: MIT University Press), 181-206.

Dennett, D. C. (1992). Consciousness Explained. New York, NY: Back Bay Books.

Dietrich, F., and List, C. (2013). Reasons for (prior) belief in Bayesian epistemology. Synthese 190, 787-808. doi: 10.1007/s11229-012-0185-9

Domschke, K., Stevens, S., Pfleiderer, B., and Gerlach, A. L. (2010). Interoceptive sensitivity in anxiety and anxiety disorders: an overview and integration of neurobiological findings. Clin. Psychol. Rev. 30, 1-11. doi: 10.1016/j.cpr.2009.08.008

Doumas, L. A. A., and Hummel, J. E. (2012). "Computational models of higher cognition," in The Oxford Handbook of Thinking and Reasoning, eds K. J. Holyoak and R. G. Morrison (New York, NY: Oxford University Press), 52-66.

Dreyfus, H. L. (1992). What Computers Still can't Do. Cambridge, MA: MIT Press. Egan, F. (2012). "Representationalism," in The Oxford Handbook of Cognitive Science, eds E. Margolis, R. Samuels, and S. P. Stich (New York, NY: Oxford University Press), 250-272.

Ellis, A. (1994). "The essence of rational emotive behavior therapy: a comprehensive approach to treatment," in Personality Theories: Critical Perspectives. Available online at: http://www.sagepub.com/personalitytheoriesstudy/01/ resources $2 . h t m$

Emmelkamp, P. M. G., Ehring, T., and Powers, M. B. (2010). "Philosophy, psychology, causes, and treatments of mental disorders," in Cognitive and Behavioral Theories in Clinical Practice, eds N. Kazantzis, M. A. Reinecke, and A. Freeman (New York, NY: Guilford Press), 1-27.

Feldman, R., and Conee, E. (1985). Evidentialism. Philos. Stud. 48, 15-34. doi: 10.1007/BF00372404

Fermé, E., and Hansson, S. O. (2011). AGM 25 years: twenty-five years of research in belief change. J. Philos. Logic 40, 295-331. doi: 10.1007/s10992-011-9171-9

Feusner, J. D., Townsend, J., Bystritsky, A., and Bookheimer, S. (2007). Visual information processing of faces in body dysmorphic disorder. Arch. Gen. Psychiat. 64, 1417-1425. doi: 10.1001/archpsyc.64.12.1417

Foa, E. B., Hembree, E. A., and Rothbaum, B. O. (2007). Prolonged Exposure Therapy for PTSD-Emotional Processing of Traumatic Experiences. New York, NY: Oxford University Press.

Fodor, J. (1975). The Language of Thought. Cambridge, MA: Harvard University Press.

Fonagy, P., Steele, M., Steele, H., Moran, G. S., and Higgitt, A. C. (1991). The capacity for understanding mental states: the reflective self in parent and child and its significance for security of attachment. Infant. Ment. Health J. 12, 201-218. doi: 10.1002/1097-0355(199123)12:3<201::AID-IMHJ2280120307>3.0.CO;2-7

Frazzetto, G. (2013). Joy, Guilt, Anger, Love: What Neuroscience Can-and Can't-Tell Us About How We Feel. New York, NY: Penguin Books.

Friedman, S. E., and Forbus, K. D. (2011). Repairing incorrect knowledge with model formulation and metareasoning. IJCAI/AAII 2011, 887-893. doi: 10.5591/978-1-57735-516-8/IJCAI11-154

Gabbay, D. M., Rodrigues, O. T., and Russo, A. (2010). "Introducing revision theory," in Revision, Acceptability and Context - Theoretical and Algorithmic Aspects, eds D. M. Gabbay, O. T. Rodrigues, and A. Russo (New York, NY: Springer Science+Business Media), 13-54. doi: 10.1007/978-3-642-14159-1_2

Galavotti, M. C. (2011). "The modern epistemic interpretation of probability: logicism and subjectivism," in Handbook of the History of Logic-Vol. 10-Inductive Logic, eds D. M. Gabbay, S. Hartmann, and J. Woods (Amsterdam, NL: Elsevier), 153-203.

Gärdenfors, P. (2011). Notes on the history of ideas behind AGM. J. Philos. Logic. 40, 115-120. doi: 10.1007/s10992-011-9174-6

Garland, E. L., Fredrickson, B., Kring, A. M., Johnson, D. P., Meyers, P. S., and Penn, D. L. (2010). Upward spirals of positive emotions counter downward spirals of negativity: insights from the broaden-and-build theory and affective neuroscience on the treatment of emotion dysfunctions and deficits in psychopathology. Clin. Psychol. Rev. 30, 849-864. doi: 10.1016/j.cpr.2010. 03.002

Gipps, R. T. (2013). "Cognitive behavior therapy: a philosophical appraisal," in The Oxford Handbook of Philosophy and Psychiatry, eds K. W. M. Fulford, M. Davies, R. G. T. Gipps, G. Graham, J. Z. Sadler, G. Stanghellini, and T. Thornton (Oxford: Oxford University Press), 1245-1263. doi: 10.1093/oxfordhb/9780199579563.013.0072

Gleitman, L., and Papafragou, A. (2012). "New perspectives on language and thought," in The Oxford Handbook of Thinking and Reasoning, eds K. J. Holyoak and R. G. Morrison (New York, NY: Oxford University Press), 543-567. 
Gleitman, L., and Papafragou, A. (2013). "Relations between language and thought," in The Oxford Handbook of Cognitive Psychology, ed D. Reisberg (Oxford: Oxford University Press), 504-523.

Glymour, C. (1975). Relevant evidence. J. Philos. 72, 403-426. doi: 10.2307/2025011

Goel, V. (2013). A new tool aims to help Facebook users dig deep. N.Y. Times. Available online at: http://www.nytimes.com/2013/07/08/technology/ a-new-tool-aims-to-help-facebook-users-dig-deep.html

Goñi, J., Arrondo, G., Sepulcre, J., Martincorena, I., Mendizábal, N. V. D., Corominas-Murtra, B., et al. (2011). The semantic organization of the animal category: evidence from semantic verbal fluency and network theory. $\operatorname{Cog} n$. Process. 12, 183-196. doi: 10.1007/s10339-010-0372-x

Grant, P. M., Huh, G. A., Perivoliotis, D., Stolar, N. M., and Beck, A. T. (2012). Randomized trial to evaluate the efficacy of cognitive therapy for lowfunctioning patients with schizophrenia. Arch. Gen. Psychiatry 69, 121-127. doi: 10.1001/archgenpsychiatry.2011.129

Greene, J. D., Sommerville, R. B., Nystrom, L. E., Darley, J. M., and Cohen, J. D. (2001). An fMRI investigation of emotional engagement in moral judgment. Science 293, 2105-2108. doi: 10.1126/science. 1062872

Grice, H. P. (1975). "Logic and conversation," in Syntax and Semantics, Vol. 3, Speech Acts, eds P. Cole and J. L. Morgan (New York, NY: Academic Press), 41-58.

Guastello, S. J., and Liebovitch, L. S. (2009). "Introduction to nonlinear dynamics and complexity," in Chaos and Complexity in Psychology-The Theory of Nonlinear Dynamical Systems, eds S. J. Guastello, M. Koopmans, and D. Pincus (Cambridge: Cambridge University Press), 1-40.

Hájek, A. (2011). Interpretations of probability. Stanford Encyclopedia Philos. Available online at: http://plato.stanford.edu/entries/probability-interpret/

Hanks, W. F. (2011). "Deixis and indexicality," in Foundations of Pragmatics, eds W. Bublitz and N. R. Norrick (Berlin, DE: De Gruyter Mouton), 315-346. doi: $10.1515 / 9783110214260.315$

Harris, S., Sheth, S. A., and Cohen, M. S. (2008). Functional neuroimaging of belief, disbelief, and uncertainty. Ann. Neurol. 63, 141-147. doi: 10.1002/ana.21301

Hartley, C. A., and Phelps, E. A. (2012). Anxiety and decision-making. Biol. Psychiatry 72, 113 -118. doi: 10.1016/j.biopsych.2011.12.027

Hartmann, S., and Sprenger, I. (2010). "Bayesian epistemology," in Routledge Companion to Epistemology, eds S. Bernecker and D. Pritchard ( London, UK: Routledge), 609-620.

Hauner, K. K., Mineka, S., Voss, J. L., and Paller, K. A. (2012). Exposure therapy triggers lasting reorganization of neural fear processing. PNAS 10, 2014. doi: 10.1073/pnas.1205242109

Hauser, M. D., Chomsky, N., and Fitch, T. (2002). The faculty of language: what is it, who has it, and how did it evolve? Science 298, 1569-1579. doi: $10.1126 /$ science.298.5598.1569

Hayes, S. C. (2004). Acceptance and commitment therapy, relational frame theory, and the third wave of behavioral and cognitive therapies. Behav. Ther. 35, 639-665. doi: 10.1016/S0005-7894(04)80013-3

Hayes, S. C., Strosahl, K. D., and Wilson, K. G. (2012). Acceptance and Commitment Therapy, 2nd Edn. New York, NY: Guilford Press.

Heisz, J. J., Vakorin, V., Ross, B., Levine, B., and McIntosh, A. R. (2014). A trade-off between local and distributed information processing associated with remote episodic versus semantic memory. J. Cogn. Neurosci. 26, 41-53. doi: 10.1162/jocn_a_00466

Heit, E., and Rotello, C. M. (2010). Relations between inductive reasoning and deductive reasoning. J. Exp. Psychol. Learn. Mem. Cogn. 36, 805-812. doi: 10.1037/a0018784

Herry, C., Ferraguti, F., Singewald, N., Letzkus, J. J., Ehrlich, I., and Lüthi, A. (2010). Neuronal circuits of fear extinction. Eur. J. Neurosci. 31, 599-612. doi: 10.1111/j.1460-9568.2010.07101.x

Hofer, M. (2010). "New concepts in the evolution and development of anxiety," in Anxiety Disorders-Theory, Research, and Clinical Perspectives, eds H. B. Simpson, Y. Neria, R. Lewis-Fernández, and F. Schneier (Cambridge: Cambridge University Press), 59-68. doi: 10.1017/CBO9780511 777578.008

Hope, D. A., Heimberg, R. G., and Turk, C. L. (2010). Managing Social AnxietyA Cognitive-Behavioral Therapy Approach, 2nd Edn. Oxford: Oxford University Press.

Howson, C. (2009). "Epistemic probability and coherent degrees of belief," in Degrees of Belief, eds F. Huber and C. Schmidt-Petri (New York, NY: Springer Science+Business Media B.V.), 97-119. doi: 10.1007/978-1-4020-9198-8_5
Huber, F. (2009). "Belief and degrees of belief," in Degrees of Belief, eds F. Huber and C. Schmidt-Petri (New York, NY: Springer Science+Business Media), 1-33. doi: 10.1007/978-1-4020-9198-8_1

Huntsinger, J. R., and Schnall, S. (2013). "Emotion-cognition interactions," in The Oxford Handbook of Cognitive Psychology, ed D. Reisberg (Oxford: Oxford University Press), 571-584.

Huppert, J. D. (2009). The building blocks of treatment in cognitive-behavioral therapy. Isr. J. Psychiat. Relat. Sci. 46, 245-250.

Huth, A. G., Nishimoto, S., Vu, A. T., and Gallant, J. L. (2012). A continuous semantic space describes the representation of thousands of object and action categories across the human brain. Neuron 76, 1210-1224. doi: 10.1016/j.neuron.2012.10.014

Jauhar, S., McKenna, P. J., Radua, J., Fung, E., Salvador, R., and Laws, K. R. (2014). Cognitive-behavioural therapy for the symptoms of schizophrenia: systematic review and meta-analysis with examination of potential bias. Br. J. Psychiatry. 204, 20-29. doi: 10.1192/bjp.bp.112.116285

Johnson-Laird, P. N. (2010). Mental models and human reasoning. Proc. Natl. Acad. Sci. U.S.A. 107, 18243-18250. doi: 10.1073/pnas.1012933107

Johnson-Laird, P. N. (2013). Mental models and cognitive change. J. Cog. Psychol. 25, 131-138. doi: 10.1080/20445911.2012.759935

Joyce, J. M. (2003). Bayes theorem. Stanford Encyclopedia Philos. Available online at: http://plato.stanford.edu/entries/bayes-theorem/

Joyce, J. M. (2009). "Accuracy and coherence: prospects for an alethic epistemology of partial belief," in Degrees of Belief, eds F. Huber and C. Schmidt-Petri (New York, NY: Springer Science+Business Media), 263-297. doi: 10.1007/9781-4020-9198-8_11

Joyce, J. M. (2011). “The development of subjective Bayesianism," in Handbook of the History of Logic-Vol. 10-Inductive Logic, eds D. M. Gabbay, S. Hartmann, and J. Woods (Amsterdam, NL: Elsevier),. 415-745.

Juarrero, A. (1999). Dynamics in Action-Intentional Behavior as a Complex System. Cambridge, MA: MIT Press.

Kahneman, D. (2003). A perspective on judgment and choice-mapping bounded rationality. Am. Psychol. 58, 697-720. doi: 10.1037/0003-066X.58.9.697?

Kahneman, D., Slovic, P., and Tversky, A. (eds.). (1982). Judgment Under Uncertainty: Heuristics and Biases. Cambridge: Cambridge University Press.

Kahneman, D., and Tversky, A. (1979). Prospect theory: an analysis of decision under risk. Econometrica 47, 263-292. doi: 10.2307/1914185

Kelso, J. A. S. (1999). Dynamic Patterns-The Self-Organization of Brain and Behavior. Cambridge, MA: MIT Press.

Khalsa, S. S., Rudrauf, D., Feinstein, J. S., and Tranel, D. (2009). The pathways of interoceptive awareness. Nat. Neurosci. 12, 1494-1496. doi: 10.1038/ nn. 2411

Khemlani, S. S., and Johnson-Laird, P. N. (2011). The need to explain. Q. J. Exper. Psychol. 64, 2276-2288. doi: 10.1080/17470218.2011.592593

Kircanski, K., Mortazavi, A., Castriotta, N., Baker, A. S., Mystkowski, J. L., Yi, R., et al. (2012). Challenges to the traditional exposure paradigm: variability in exposure therapy for contamination fears. J. Behav. Ther. Exp. Psychiatry 43, 745-751. doi: 10.1016/j.jbtep.2011.10.010

Kuhn, T. S. (1962/2012). The Structure of Scientific Revolutions. Chicago, IL: University of Chicago Press.

Kuyken, W., Watkins, E., Holden, E., White, K., Taylor, R. S., Byford, S., et al. (2010). How does mindfulness-based cognitive therapy work? Behav. Res. Ther. 48, 1105-1112. doi: 10.1016/j.brat.2010.08.003

Langdon, R., and Connaughton, E. (2013). "The neuropsychology of belief formation," in The Neural Basis of Human Belief Systems, eds F. Krueger and J. Grafman (New York, NY: Psychology Press), 19-42.

Laurence, S., and Margolis, E. (2012). "The scope of the conceptual," in The Oxford Handbook of Philosophy of Cognitive Science, eds E. Margolis, R. Samuels, and S. P. Stich (New York, NY: Oxford University Press), 291-317.

Leahy, R. L. (2001). Overcoming Resistance in Cognitive Therapy. New York, NY: Guilford Press.

Leahy, R. L. (2005). “Cognitive therapy,” in Psychological Treatment of Bipolar Disorder, eds S. L. Johnson and R. L. Leahy (New York, NY: Guilford Press), 139-161.

Leahy, R. L., and Rego, S. A. (2012). "What is cognitive restructuring?" in Cognitive Behavior Therapy: Core Principles for Practice, eds W. T. O’Donohue and J. E. Fisher (Hoboken, NJ: John Wiley and Sons, Inc.), 133-158. doi: 10.1002/9781118470886.ch6 
Lecher, C. (2014). Stephen Wolfram wants to make computer language more human. Popular Science. Available online at: http://www.popsci.com/article/ technology/stephen-wolfram-wants-make-computer-language-more-human

LeDoux, J. (1996). The Emotional Brain. New York, NY: Touchstone.

Lee, J. K., Orsillo, S. M., Roemer, L., and Allen, L. B. (2010). Distress and avoidance in generalized anxiety disorder: exploring the relationships with intolerance of uncertainty and worry. Cogn. Behav. Ther. 39, 126-136. doi: $10.1080 / 16506070902966918$

Levine, J. (1983). Materialism and qualia: the explanatory gap. Pac. Philos. Quart. 64, 354-361.

Levine, J. (1999). "Conceivability, identity, and the explanatory gap," in Toward a science of consciousness III: The third Tucson discussions and debates (complex adaptive systems), eds S. R. Hameroff, A. W. Kaszniak, and D. Chalmers (Cambridge, MA: MIT University Press), 3-12.

Lieberman, M. D., Eisenberger, N. I., Crockett, M. J., Tom, S. M., Pfeifer, J. H., and Way, B. M. (2007). Putting feelings into words. Psychol. Sci. 18, 421-428. doi: 10.1111/j.1467-9280.2007.01916.x

Lightsey, O. R., Johnson, E., and Freeman, P. (2012). Can positive thinking reduce negative affect? A test of potential mediating mechanisms. J. Cogn. Psychol. 26, 71-88. doi: 10.1891/0889-8391.26.1.71

Linehan, M. M. (1993). Cognitive-Behavioral Treatment of Borderline Personality Disorder. New York, NY: Guilford Press.

Liu, W., McTear, M. F., and Hong, J. (1991). "Propagating beliefs among frames of discernment in Dempster-Shafer theory," in AI and Cognitive Science'90, eds M. F. McTear and N. Creaney (London, UK: Springer-Verlag), 367-377.

Longmore, R. J., and Worrell, M. (2007). Do we need to challenge thoughts in cognitive behavior therapy? Clin. Psychol. Rev. 27, 173-187. doi: 10.1016/j.cpr.2006.08.001

Lynch, T. R., Chapman, A. L., Rosenthal, M. Z., Kuo, J. R., and Linehan, M. M. (2006). Mechanisms of change in dialectical behavior therapy: theoretical and empirical observations. J. Clin. Psychol. 62, 459-480. doi: 10.1002/jclp.20243

Macleod, C. (2010). Current directions at the juncture of clinical and cognitive science: a commentary on the special issue. Appl. Cognit. Psychol. 24, 450-463. doi: $10.1002 /$ acp. 1697

Makinson, D. (2003). Ways of doing logic: what was new about AGM 1985. J. Logic. Comput. 13, 5-15.

Makinson, D. (2009). "Levels of belief in nonmonotonic reasoning," in Degrees of Belief, eds F. Huber and C. Schmidt-Petri (New York, NY: Springer Science+Business Media), 341-354. doi: 10.1007/978-1-4020-9198-8_13

Markman, A. B. (2012). "Knowledge representation," in The Oxford Handbook of Thinking and Reasoning, eds K. J. Holyoak and R. G. Morrison (New York, NY: Oxford University Press), 36-51.

Markoff, J. (2012). How many computers to identify a cat? 16,000. N.Y. Times. Available online at: http://www.nytimes.com/2012/06/26/technology/in-a-bignetwork-of-computers-evidence-of-machine-learning.html?pagewanted=all

Martin, L. (1986). Eskimo words for snow: a case study in the genesis and decay of an anthropological example. Am. Anthropol. 88, 418-423. doi: 10.1525/aa.1986.88.2.02a00080

Marupaka, N., Iyer, L. R., and Minai, A. A. (2012). Connectivity and thought: the influence of semantic network structure in a neurodynamical model of thinking. Neural. Netw. 32, 147-158. doi: 10.1016/j.neunet.2012.02.004

Matthews, E. (2013). "Mental disorder: can Merleau-Ponty take us beyond the mind-brain problem," in The Oxford Handbook of Philosophy and Psychiatry, eds K. W. M. Fulford, M. Davies, R. G. T. Gipps, G. Graham, J. Z. Sadler, G. Stanghellini, and T. Thornton (Oxford: Oxford University Press), 531-544. doi: 10.1093/oxfordhb/9780199579563.013.0033

McCullough, J. P. (2000). Treatment for Chronic Depression: Cognitive Behavioral Analysis System of Psychotherapy (CBASP). New York, NY: Guilford Press.

McGrath, M. (2012). Propositions. Stanford Encyclopedia Philos. Available online at: http://plato.stanford.edu/entries/propositions/

McMillan, D., and Lee, R. (2010). A systematic review of behavioral experiments vs. exposure alone in the treatment of anxiety disorders: a case of exposure while wearing the emperor's new clothes? Clin. Psychol. Rev. 30, 467-478. doi: 10.1016/j.cpr.2010.01.003

McRae, K., and Jones, M. (2013). "Semantic memory," in The Oxford Handbook of Cognitive Psychology, D. Reisberg (Oxford: Oxford University Press), 206-219.

Meacham, C. J. G., and Weisberg, J. (2011). Representation theorems and the foundations of decision theory. Australas. J. Philos. 89, 641-663. doi: $10.1080 / 00048402.2010 .510529$
Michalewicz, Z., and Fogel, D. (2004). How to Solve it: Modern Heuristics, 2nd Edn. New York, NY: Springer Verlag. doi: 10.1007/978-3-662-07807-5

Miller, C. C. (2013). Google alters search to handle more complex queries. N.Y. Times. Available online at: http://bits.blogs.nytimes.com/2013/09/26/ google-changes-search-to-handle-more-complex-queries/?_r=0

Miller, W. R., and Rollnick, S. (2012). Motivational Interviewing: Helping People Change, 3rd Edn. New York, NY: Guilford Press.

Möller, H.-J. (2012). How close is evidence to truth in evidence-based treatment of mental disorders? Eur. Arch. Psychiat. Clin. Neurosci. 262, 277-289. doi: 10.1007/s00406-011-0273-8

Morina, N., Deeprose, C., Pusowski, C., Schmid, M., and Holmes, E. A. (2011). Prospective mental imagery in patients with major depressive disorder or anxiety disorders. J. Anxiety Disord. 25, 1032-1037. doi: 10.1016/j.janxdis.2011.06.012

Morrison, R. G., and Knowlton, B. J. (2012). "Neurocognitive methods in higher cognition," in The Oxford Handbook of Thinking and Reasoning, eds K. J. Holyoak and R. G. Morrison (New York, NY: Oxford University Press), 67-89.

Moser, J. S., Hartwig, R., Moran, T. P., Jendrusina, A. A., and Kross, E. (2014). Neural markers of positive appraisal and their associations with trait reappraisal and worry. J. Abnorm. Psychol. 123, 91-105. doi: 10.1037/a0035817

Musil, R. (1930-43). Der Mann Ohne Eigenschaften. Vienna, AU: Rowohlt Verlag.

Nelson, D. L., Kitto, K., Galea, D., McEvoy, C. L., and Bruza, P. D. (2013). How activation, entanglement, and searching a semantic network contribute to event memory. Mem. Cognit. 41, 797-819. doi: 10.3758/s13421-013-0312-y

Nelson, E. A., Deacon, B. J., Lickel, J. J., and Sy, J. T. (2010a). Targeting the probability versus cost of feared outcomes in public speaking anxiety. Behav. Res. Ther. 48, 282-289. doi: 10.1016/j.brat.2009.11.007

Nelson, E. A., Lickel, J. J., Sy, J. T., Dixon, L. J., and Deacon, B. J. (2010b). Probability and cost biases in social phobia: nature, specificity, and relationship to treatment outcome. J. Cogn. Psychol. 24, 213-228. doi: 10.1891/0889-8391.24.3.213

Newman, M. G., and Llera, S. J. (2011). A novel theory of experiential avoidance in generalized anxiety disorder: a review and synthesis of research supporting a contrast avoidance model of worry. Clin. Psychol. Rev. 31, 371-382. doi: 10.1016/j.cpr.2011.01.008

Nicolis, G., and Prigogine, I. (1989). Exploring Complexity. New York, NY: W. H. Freeman and Company.

Noë, A. (2004). Action in Perception. Cambridge, MA: MIT Press.

Oaksford, M., and Chater, N. (2007). Bayesian Rationality: The Probabilistic Approach to Human Reasoning. Oxford: Oxford University Press. doi: 10.1093/acprof:oso/9780198524496.001.0001

Ohlsson, S. (2011). Deep Learning: How the Mind Overrides Experience. Cambridge: Cambridge University Press. doi: 10.1017/CBO9780511780295

Olthuis, J. V., Stewart, S. H., Watt, M. C., Sabourin, B. C., and Keogh, E. (2012). Anxiety sensitivity and negative interpretation biases: their shared and unique associations with anxiety symptoms. J. Psychopathol. Behav. 34, 332-342. doi: 10.1007/s10862-012-9286-5

Patterson, R., and Barbey, A. K. (2013). "A multiple systems approach to causal reasoning," in The Neural Basis of Human Belief Systems, eds F. Krueger and J. Grafman (New York, NY: Psychology Press), 43-71.

Paulus, M. P., and Stein, M. B. (2010). Interoception in anxiety and depression. Brain Struct. Funct. 214, 451-463. doi: 10.1007/s00429-010-0258-9

Pavlov, I. (1927/2003). Conditioned Reflexes. Mineola, NY: Dover Publications.

Pecher, D. (2013). "The perceptual representation of mental categories," in The Oxford Handbook of Cognitive Psychology, ed D. Reisberg (Oxford: Oxford University Press), 358-373.

Perring, C. (2010). Mental illness. Stanford Encyclopedia Philos. Available online at: http://plato.stanford.edu/entries/mental-illness/

Persons, J. B., Roberts, N. A., Zalecki, C. A., and Brechwald, W. A. G. (2006). Naturalistic outcome of case formulation-driven cognitive-behavior therapy for anxious depressed outpatients. Behav. Res. Ther. 44, 1041-1051. doi: 10.1016/j.brat.2005.08.005

Pessoa, L. (2008). On the relationship between emotion and cognition. Nat. Rev. Neurosci. 9, 148-158. doi: 10.1038/nrn2317

Pessoa, L. (2014). “The impact of emotion on cognition," in The Oxford Handbook of Cognitive Neuroscience, vol. 2, eds K. N. Ochsner and S. M. Kosslyn (Oxford: Oxford University Press), 79-93.

Piantadosi, S. T., Tily, H., and Gibson, E. (2012). The communicative function of ambiguity in language. Cognition 122, 280-291. doi: 10.1016/j.cognition.2011. 10.004 
Poldrack, R. A., Kittur, A., Kalar, D., Miller, E., Seppa, C., Gil, Y., et al. (2011). The cognitive atlas: toward a knowledge foundation for cognitive neuroscience. Front. Neuroinform. 5:17. doi: 10.3389/fninf.2011.00017

Princeton University. (2010). About WordNet. Available online at: http://wordnet. princeton.edu/wordnet/

Quine, W. V. O. (1953/1980). “Two dogmas of empiricism," in From a Logical Point of View, 2nd Revised Edn. (New York, NY: Harper and Row), 20-46.

Quine, W. V. O. (1964). Word and Object. Cambridge, MA: MIT University Press.

Quine, W. V. O., and Ullian, J.S. (1978). The Web of Belief, 2nd Edn. Columbus, OH: McGraw-Hill.

Rabinovich, M. I., Afraimovich, V. S., Bick, C., and Varona, P. (2012a). Information flow dynamics in the brain. Phys. Life Rev. 9, 51-73. doi: 10.1016/j.plrev.2011. 11.002

Rabinovich, M. I., Afraimovich, V. S., Bick, C., and Varona, P. (2012b). Instability, semantic dynamics and modeling brain data. Phys. Life. Rev. 9, 80-83. doi: 10.1016/j.plrev.2012.01.003

Rabinovich, M. I., Afraimovich, V. S., and Varona, P. (2010b). Heteroclinic binding. Dynam. Syst. 25, 433-442. doi: 10.1080/14689367.2010.515396

Rabinovich, M. I., Muezzinoglu, M. K., Strigo, I., and Bystritsky, A. (2010a). Dynamical principles of emotion-cognition interaction: mathematical images of mental disorders. PLOS ONE 5:e12547. doi: 10.1371/journal.pone. 0012547

Rabinovich, M. I., Varona, P., Tristan, I., and Afraimovich, V. S. (2014). Chunking dynamics: heteroclinics in mind. Front. Comput. Neurosci. 8:1-22. doi: 10.3389/fncom.2014.00022

Reardon, S. (2014). Brain-mapping projects to join forces. Nature doi: $10.1038 /$ nature.2014.14871. (in press).

Reisberg, D. (2014). "Mental images," in The Oxford Handbook of Cognitive Psychology, ed D. Reisberg (Oxford: Oxford University Press), 374-390. doi: 10.1093/oxfordhb/9780195376746.001.0001

Rescorla, R. A., and Wagner, A. R. (1972). "A theory of pavlovian conditioning: variations in the effectiveness of reinforcement and nonreinforcement," in Classical Conditioning II: Current Research and Theory, eds A. H. Black and W. F. Prokasy (New York, NY: Appleton-Century-Crofts), 64-99.

Resick, P. A., Nishith, P., Weaver, T. L., Astin, M. C., and Feuer, C. A. (2002). A comparison of cognitive-processing therapy with prolonged exposure and a waiting condition for the treatment of chronic posttraumatic stress disorder in female rape victims. J. Consult. Clin. Psychol. 70, 867-879. doi: 10.1037/0022006X.70.4.867

Rhodes, J., and Gipps, R. G. T. (2008). Delusions, certainty, and the background. Philos. Psychiatry Psychol. 15, 295-310. doi: 10.1353/ppp.0.0202

Rips, L. J., Smith, E. E., and Medin, D. L. (2012). "Concepts and categories: memory, meaning, and metaphysics," in The Oxford Handbook of Thinking and Reasoning, eds K. J. Holyoak and R. G. Morrison (New York, NY: Oxford University Press), 177-209.

Roemer, L., Orsillo, S. M., and Barlow, D. H. (2002). "Generalized anxiety disorder," in Anxiety and Its Disorders, 2nd Edn., ed D. H. Barlow (New York, NY: Guilford Press), 477-515.

Russell, B. (1921/2005). The Analysis of Mind. Mineola, NY: Dover Publications, Inc.

Ruths, J., and Ruths, D. (2014). Control profiles of complex networks. Science 343, 1373-1376. doi: 10.1126/science. 1242063

Ryle, G. (1949/2009). The Concept of Mind. New York, NY: Routledge.

Samanez-Larkin, G. R., Hollon, N. G., Carstensen, L. L., and Knutson, B. (2008). Individual differences in insular sensitivity during loss anticipation predict avoidance learning. Psychol. Sci. 19, 320-323. doi: 10.1111/j.14679280.2008.02087.x

Samuels, S. (2012). "Massive modularity" in The Oxford Handbook of Philosophy of Cognitive Science, eds E. Margolis, R. Samuels, and S. P. Stich (New York, NY: Oxford University Press), 60-91. doi: 10.1093/oxfordhb/9780195309799. 003.0004

Saxe, R., and Young, L. L. (2014). "Theory of mind: how brains think about thoughts," in The Oxford Handbook of Cognitive Neuroscience, Vol. 2, eds K. N. Ochsner and S. M. Kosslyn (Oxford: Oxford University Press), 204-213.

Scholz, B. C. (2011). Philosophy of linguistics. Stanford Encyclopedia Philos. Available online at: http://plato.stanford.edu/entries/linguistics/

Schraw, G., and Dennison, R. S. (1994). Assessing metacognitive awareness. Contemp. Educ. Psychol. 19, 460-475. doi: 10.1006/ceps.1994.1033
Schroeter, L. (2012). Two-dimensional semantics. Stanford Encyclopedia Philos. Available online at: http://plato.stanford.edu/archives/win2012/ entries/two-dimensional-semantics/

Schultz, L. T., and Heimberg, R. G. (2008). Attentional focus in social anxiety disorder: potential for interactive processes. Clin. Psychol. Rev. 28, 1206-1221. doi: 10.1016/j.cpr.2008.04.003

Schwitzgebel, E. (2010). Belief. Stanford Encyclopedia Philos. Available online at: http://plato.stanford.edu/entries/belief/

Searle, J. R. (1983). Intentionality. Cambridge: Cambridge University Press. doi: 10.1017/CBO9781139173452

Searle, J. R. (1992). The Rediscovery of the Mind. Cambridge, MA: MIT Press.

Searle, J. R. (1995). The Construction of Social Reality. New York, NY: Free Press.

Searle, J. R. (2007). "What is language: some preliminary remarks," in Explorations in Pragmatics-Linguistic, Cognitive and Intercultural Aspects, eds I. Kecskes, and L. R. Horn (Berlin, DE: Walter de Gruyter GmbH and Co.), 7-38. Reprinted in (2007). John Searle's Philosophy of Language: Force, Meaning and Mind, ed S. L. Tsohatzidis (Cambridge: Cambridge University Press), 15-46. Also reprinted in (2009). Ethics Politics, 9, 173-202.

Searle, J. R. (2010). Making the Social World. Oxford: Oxford University Press.

Segerberg, K., Meyer, J.-J., and Kracht, M. (2009). The logic of action. Stanford Encyclopedia Philos. Available online at: http://plato.stanford.edu/ entries/logic-action/

Sengupta, S. (2013). Facebook unveils a new search tool. N.Y. Times. Available online at: http://bits.blogs.nytimes.com/2013/01/15/facebookunveils-a-new-search-tool/

Shafer, G., and Tversky, A. (1985). Languages and designs for probability judgment. Cogn. Sci. 9, 309-339. doi: 10.1207/s15516709cog0903_2

Shanahan, M. (2009). The frame problem. Stanford Encyclopedia Philos. Available online at: http://plato.stanford.edu/entries/frame-problem/

Shea, N. (2013). "Neural mechanisms of decision-making and the personal level," in The Oxford Handbook of Philosophy and Psychiatry, eds K. W. M. Fulford, M. Davies, R. G. T. Gipps, G. Graham, J. Z. Sadler, G. Stanghellini, and T. Thornton (Oxford: Oxford University Press), 1063-1082. doi: 10.1093/ oxfordhb/xya9780199579563.013.0062

Shermer, M. (2012). The Believing Brain. New York, NY: Henry Holt and Co.

Siddique, H. (2014). World's First Computational Psychiatry Centre Opens in London. The Guardian. Available online at: http://www.theguardian.com/ science/2014/apr/02/worlds-first-computational-psychiatry-centre-london

Simmons, A., Strigo, I., Matthews, S. C., Paulus, M. P., and Stein, M. B. (2006). Anticipation of aversive visual stimuli is associated with increased insula activation in anxiety-prone subjects. Biol. Psychiatry 60, 402-409. doi: 10.1016/j.biopsych.2006.04.038

Skinner, B. F. (1947). Superstition in the pigeon. J. Exp. Psychol. 38, 168-172. doi: $10.1037 / \mathrm{h} 0055873$

Skinner, B. F. (1957/1991). Verbal Behavior. Acton, MA: Copley Publishing Group.

Smits, J. A., Berry, A. C., Tart, C. D., and Powers, M. B. (2008). The efficacy of cognitive-behavioral interventions for reducing anxiety sensitivity: a meta-analytic review. Behav. Res. Ther. 46, 1047-1054. doi: 10.1016/j.brat.2008. 06.010

SNePS. Research Group. (2013). SNePS. Available online at: http://www.cse buffalo.edu/sneps/

Snow, C. P. (1959/2012). The Two Cultures. Cambridge: Cambridge University Press.

Solé, R., and Seoane, L. (2014). Ambiguity in language networks. Phys. Soc. Available online at: http://arxiv.org/abs/1402.4802

Sonnemann, U., Camerer, C. F., Fox, C. R., and Langer, T. (2013). How psychological framing affects economic market prices in the lab and field. Proc. Natl. Acad. Sci. U.S.A. 110, 11779-11784. doi: 10.1073/pnas.1206326110

Spiegler, M. D., and Guevremont, D. C. (2009). Contemporary Behavior Therapy. Independence, MO: Wadsworth Publishing.

Spohn, W. (2009). "A survey of ranking theory," in Degrees of Belief, eds F. Huber and C. Schmidt-Petri (New York, NY: Springer Science+Business Media), 185-228. doi: 10.1007/978-1-4020-9198-8_8

Sporns, O., Tononi, G., and Kötter, R. (2005). The human connectome: a structural description of the human brain. PLoS Comput. Biol. 1:e42. doi: 10.1371/journal.pcbi.0010042

Squire, L. R., and Kandel, E. R. (1998). Memory: From Mind to Molecules. New York, NY: Scientific American Library. 
Stone, M. (2014). "Semantics and computational semantics," in Cambridge Handbook of Semantics (forthcoming), eds P. Dekker and M. Aloni (Cambridge: Cambridge University Press). Available online at: http://www.cs. rutgers.edu/ $\sim$ mdstone/pubs/compsem13.pdf

Studdert-Kennedy, M. (2005). "How did language go discrete?" in Language Origins-Perspectives on Evolution, ed M. Tallerman ( Oxford: Oxford University Press), 48-67.

Stumpf, M. P., Thorne, T., de Silva, E., Stewart, R., An, H. J., Lappe, M., et al. (2008). Estimating the size of the human interactome. Proc. Natl. Acad. Sci. U.S.A. 105, 6959-6964. doi: 10.1073/pnas.0708078105

Swinburne, R. (2011). "Evidence," in Evidentialism and Its Discontents, ed T. Dougherty (Oxford: Oxford University Press), 195-206. doi: 10.1093/acprof:oso/9780199563500.003.0013

Swoyer, C. (2003). The linguistic relativity hypothesis. Stanford Encyclopedia Philos. Available online at: http://plato.stanford.edu/entries/relativism/ supplement2.html

Taylor, C. T., and Alden, L. E. (2010). Safety behaviors and judgmental biases in social anxiety disorder. Behav. Res. Ther. 48, 226-237. doi: 10.1016/j.brat.2009. 11.005

Thelen, E., and Smith, L. B. (2000). A Dynamic Systems Approach to the Deelopment of Cognition and Action. Cambridge, MA: MIT Press.

Trouche, S., Sasaki, J. M., Tu, T., and Reijmers, L. G. (2013). Fear extinction causes target-specific remodeling of perisomatic inhibitory synapses. Neuron 80 , 1054-1065. doi: 10.1016/j.neuron.2013.07.047

Tryon, W. W., and McKay, D. (2009). Memory modification as an outcome variable in anxiety disorder treatment. J. Anx. Disord. 23, 546-556. doi: 10.1016/j.janxdis.2008.11.003

Tversky, A., and Kahneman, D. (1983). Extensional versus intuitive reasoning: the conjunction fallacy in probability judgment. Psychol. Rev. 90, 293-315. doi: 10.1037/0033-295X.90.4.293

University of Colorado Boulder. (1998). What is LSA? Available online at: http:// lsa.colorado.edu

Vance, A. (2010). In pursuit of a mind map, slice by slice. N.Y. Times Available online at: http://www.nytimes.com/2010/12/28/science/28brain. html?pagewanted $=$ all

van Gulick, R. (2004). Consciousness. Stanford Encyclopedia Philos. Available online at: http://plato.stanford.edu/entries/consciousness/

Wallsten, T. S., Budescu, D. V., Erev, I., and Diederich, A. (1997). Evaluating and combining subjective probability estimates. J. Behav. Decis. Making 10, 243-268. doi: 10.1002/(SICI)1099-0771(199709)10:3\%3C243::AIDBDM268\%3E3.0.CO;2-M

Warman, D. M., Lysaker, P. H., Martin, J. M., Davis, L., and Haudenschield, S. L. (2007). Jumping to conclusions and the continuum of delusional beliefs. Behav. Res. Ther. 45, 1255-1269. doi: 10.1016/j.brat.2006.09.002

Weisberg, J. (2011). "Varieties of bayesianism," in Handbook of the History of Logic-Vol. 10-Inductive Logic, eds D. M. Gabbay, S. Hartmann, and J. Woods (Amsterdam: Elsevier), 477-551.
Wells, A. (2006). "Anxiety disorders, metacognition, and change," in Roadblocks in Cognitive-Behavioral Therapy: Transforming Challenges into Opportunities for Change, ed R. L. Leahy (New York, NY: Guilford Press), 69-90.

Wilson-Mendenhall, C. D., Simmons, W. K., Martin, A., and Barsalou, L. W. (2013). Contextual processing of abstract concepts reveals neural representations of nonlinguistic semantic content. J. Cogn. Neurosci. 25, 920-935. doi: 10.1162/jocn_a_00361

Woody, S. R., and Nosen, E. (2009). "Psychological models of phobic disorders and panic," in Oxford Handbook of Anxiety and Related Disorders, eds M. M. Anthony, and M. B. Stein (Oxford: Oxford University Press), 209-224.

Wortham, J. (2010). Apple Buys A Start-Up For Its Voice Technology. Available online at: http://www.nytimes.com/2010/04/29/technology/29apple.html

Yee, E., Chrysikou, E. G., and Thompson-Schill, S. L. (2014). "Semantic memory," in The Oxford Handbook of Cognitive Neuroscience, Vol. 1, eds K. N. Ochsner, and S. M. Kosslyn (New York, NY: Oxford University Press), 353-374.

Zalta, E. N. (2012). Gottlob Frege. Stanford Enyclopedia Philos. Available online at: http://plato.stanford.edu/entries/frege/

Zanov, M. V., and Davison, G. C. (2010). A conceptual and empirical review of 25 years of cognitive assessment using the articulated thoughts in simulated situations (ATSS) think-aloud paradigm. Cognitive Ther. Res. 34, 282-291. doi: 10.1007/s10608-009-9271-9

Zhao, J., Crupi, V., Tentori, K., Fitelson, B., and Osherson, D. (2012). Updating: learning versus supposing. Cognition 124, 373-378. doi: 10.1016/j.cognition. 2012.05.001

Zhao, J., and Osherson, D. (2010). Updating beliefs in light of uncertain evidence: descriptive assessment of Jeffrey's rule. Think. Reasoning. 16, 288-307. doi: $10.1080 / 13546783.2010 .521695$

Conflict of Interest Statement: The authors declare that the research was conducted in the absence of any commercial or financial relationships that could be construed as a potential conflict of interest.

Received: 30 January 2014; paper pending published: 21 February 2014; accepted: 24 April 2014; published online: 15 May 2014.

Citation: Kronemyer D and Bystritsky A (2014) A non-linear dynamical approach to belief revision in cognitive behavioral therapy. Front. Comput. Neurosci. 8:55. doi: 10.3389/fncom.2014.00055

This article was submitted to the journal Frontiers in Computational Neuroscience. Copyright (c) 2014 Kronemyer and Bystritsky. This is an open-access article distributed under the terms of the Creative Commons Attribution License (CC BY). The use, distribution or reproduction in other forums is permitted, provided the original author(s) or licensor are credited and that the original publication in this journal is cited, in accordance with accepted academic practice. No use, distribution or reproduction is permitted which does not comply with these terms. 